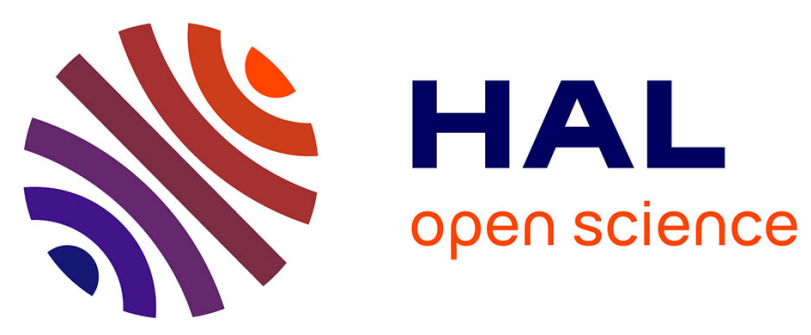

\title{
Classical Polarizable Force Field To Study Hydrated Charged Clays and Zeolites
}

Stéphane Tesson, Wilfried Louisfrema, Mathieu Salanne, Anne Boutin, Eric Ferrage, Benjamin Rotenberg, Virginie Marry

\section{- To cite this version:}

Stéphane Tesson, Wilfried Louisfrema, Mathieu Salanne, Anne Boutin, Eric Ferrage, et al.. Classical Polarizable Force Field To Study Hydrated Charged Clays and Zeolites. Journal of Physical Chemistry C, 2018, 122 (43), pp.24690-24704. 10.1021/acs.jpcc.8b06230 . hal-01905930

\section{HAL Id: hal-01905930 \\ https://hal.sorbonne-universite.fr/hal-01905930}

Submitted on 26 Oct 2018

HAL is a multi-disciplinary open access archive for the deposit and dissemination of scientific research documents, whether they are published or not. The documents may come from teaching and research institutions in France or abroad, or from public or private research centers.
L'archive ouverte pluridisciplinaire HAL, est destinée au dépôt et à la diffusion de documents scientifiques de niveau recherche, publiés ou non, émanant des établissements d'enseignement et de recherche français ou étrangers, des laboratoires publics ou privés. 


\section{Classical Polarizable Force Field to Study Hydrated Charged Clays and Zeolites}

Stéphane Tesson, ${ }^{\dagger}$ Wilfried Louisfrema, ${ }^{\dagger},{ }^{\dagger}$ Mathieu Salanne, ${ }^{\dagger}$ Anne Boutin,${ }^{\ddagger}$ Eric Ferrage, ${ }^{\mathbb{I}}$ Benjamin Rotenberg, ${ }^{\dagger}$ and Virginie Marry ${ }^{*, \dagger}$

Sorbonne Université, CNRS, Physicochimie des électrolytes et nanosystèmes interfaciaux, UMR PHENIX, F-75005, Paris, France,

PASTEUR, Département de Chimie Ecole Normale Supérieure, PSL University, Sorbonne Université, CNRS, 75005 Paris, France, and Université de Poitiers, CNRS, UMR 7285 IC2MP,

Equipe HydrASA, 5 rue Albert Turpain, Bât. B8, TSA - 51106, 86073 Poitiers cedex 9, France

E-mail: virginie.marry@sorbonne-universite.fr

${ }^{*}$ To whom correspondence should be addressed

†UPMC

${ }^{\ddagger}$ ENS

IHYDRASA 


\begin{abstract}
Following our previous works on dry clays, we extend the classical Polarizable Ion Model (PIM) to hydrated dioctahedral clays, by considering Na-, Cs-, Ca- and Sr-montmorillonites in the mono- and bihydrated states. The parameters of the force field are determined by optimizing the atomic forces and dipoles on density functional theory calculations. The simulation results are compared with results obtained with CLAYFF force field and validated by comparison with experiment. The X-Ray diffraction patterns calculated from classical molecular dynamics simulations performed with the PIM force field are in very good agreement with experiments. We also demonstrate the transferablity of PIM force field to other aluminosilicates, here a faujasite-type zeolite compensated with $\mathrm{Na}^{+}$, with a significant improvement in cation locations compared to non-polarizable force fields.
\end{abstract}




\section{Introduction}

Clay minerals such as montmorillonite and zeolites such as faujasite, are nanoporous aluminosilicate materials extensively used in industrial applications, such as catalytic activities, energy and environmental engineering, etc. because of their remarkable properties of adsorption and retention at the mineral surface. Under several constraints (temperature, pressure, saturation conditions, etc.) the structure of such materials may change resulting e.g. in swelling. A correct description of the properties of water contained in these materials is crucial in order to explain and predict the sorption and transport properties of the mobile species.

The behavior of these materials towards water strongly depends on the negative charge of the mineral framework and the type and the location of the compensating cations. In the case of smectite clays, it is well-known that different hydration states/layer may coexist due to structural heterogeneities affecting the layer charge distribution and location. ${ }^{1,2}$ As a consequence, it can be difficult to deduce the microscopic properties of the confined fluid from experiments.

Molecular simulations are a unique tool to describe these systems at the microscopic scale and many computational studies have been performed to better understand their physicochemical properties. $^{3-19}$ The benefit of combining molecular simulations with experiments is twofold: on one hand, the detailed description of the system obtained by molecular simulations helps interpreting the experiments; on the other hand, discrepancies between experiment and simulation data point out problems in experimental analysis and/or molecular models used for the simulations.

For clays as for zeolites, the classical force fields used to simulate the systems give results which are not always in quantitative agreement with experiment ${ }^{15,20-24}$ and there is room for refinement in the description of these systems at the atomic scale. Most of the existing force fields ${ }^{25-34}$ do not take into account the polarizability of atoms, even though an electric field exists at the mineral surface which may influence the polarization of ions and water, as well as their mobility through the mineral porosity. The importance of the polarizability has been shown to be

important to study the hydration of ions, ${ }^{35-37}$ and in other fields such as biochemistry, ${ }^{38-40}$ for which successful force fields such as CHARMM or AMOEBA have been introduced. ${ }^{41,42}$ In order 
to include this important physical effect, we have recently extended the force field based on the Polarizable Ion Model (PIM) to study clay minerals and zeolites. In addition to polarizability, the structures of clay and zeolite are flexible, which allows the deformation of the framework under the action of the fluid. We already demonstrated the ability of PIM to correctly describe their microstructure in the dry state. ${ }^{43,44}$

In the present work, we extend the PIM force field to hydrated charged montmorillonite clays. The structure of montmorillonite consists of two sheets of tetrahedra $\left(\mathrm{SiO}_{4}\right.$ tetrahedra) sandwiched to the top and bottom of a sheet of octahedra $\left(\mathrm{AlO}_{4}(\mathrm{OH})_{2}\right.$ octahedra). Some octahedral aluminum $\mathrm{Al}^{3+}$ atoms are replaced by magnesium $\mathrm{Mg}^{2+}$, resulting in a negative charge of the sheet compensated by counterions located in the interlayer space. We investigate trans-vacant-montmorillonite (tv-montmorillonite) and cis-vacant-montmorillonite ( $c v$-montmorillonite), with the counterions $\mathrm{Na}^{+}, \mathrm{Cs}^{+}, \mathrm{Ca}^{2+}$, and $\mathrm{Sr}^{2+}$. The structures are the same as those described in detail in our previous study on dry montmorillonites. ${ }^{44}$ Two hydration states corresponding to two different relative humidies are studied: the monohydrated state and bihydrated state, with one or two layers of water in the interlayer space, respectively. The fluid properties obtained with the PIM force field are then compared with the ones given by the state-of-the-art non-polarizable force field CLAYFF, and confronted to experimental data such as X-ray diffraction for the structure and neutron scattering for the dynamics. Then, we assess the transferability of the PIM force field to the case of hydrated faujasite zeolite.

\section{Method}

\section{The Polarizable Ion Model}

The total potential ( $\mathrm{V}_{\text {Total }}$ ) of the Polarizable Ion Model (PIM) is composed of four terms:

$$
\mathrm{V}_{\text {Total }}=\mathrm{V}_{\text {Charge }}+\mathrm{V}_{\text {Dispersion }}+\mathrm{V}_{\text {Repulsion }}+\mathrm{V}_{\text {Polarization }}
$$


The first term $\left(\mathrm{V}_{\text {Charge }}\right)$ represents the coulombic interactions between atomic charges. The second term $\left(\mathrm{V}_{\text {Dispersion }}\right)$ accounts for the instantaneous correlations of density fluctuations between the electronic clouds: ${ }^{45-47}$

$$
\mathrm{V}_{\text {Dispersion }}=-\sum_{i<j}\left[f_{6}^{i j}\left(r_{i j}\right) \frac{C_{6}^{i j}}{\left(r_{i j}\right)^{6}}+f_{8}^{i j}\left(r_{i j}\right) \frac{C_{8}^{i j}}{\left(r_{i j}\right)^{8}}\right],
$$

where $r_{i j}$ is the distance between atom $i$ and atom $j$, and $C_{6}^{i j}$ and $C_{8}^{i j}$ are the dipole-dipole and dipole-quadrupole dispersion coefficients. The Tang-Toennies damping functions $f_{n}^{i j}$ are used to correct the short-range interaction: ${ }^{48}$

$$
f_{n}^{i j}\left(r_{i j}\right)=1-e^{-b_{n}^{i j} r_{i j}} \sum_{k=0}^{n} \frac{\left(b_{n}^{i j} r_{i j}\right)^{k}}{k !}
$$

The repulsion term in Eq. (1) is given by

$$
\mathrm{V}_{\text {Repulsion }}=\sum_{i<j} A_{i j} e^{-B_{i j} r_{i j}}
$$

Finally, the polarization term in Eq. (1) is defined as:

$$
\begin{aligned}
\mathrm{V}_{\text {Polarization }}= & \sum_{\mathrm{i}<\mathrm{j}}\left[\frac{\mathrm{q}_{\mathrm{i}} \mathbf{r}_{\mathrm{ij}} \cdot \boldsymbol{\mu}_{\mathrm{j}}}{\mathrm{r}_{\mathrm{ij}}^{3}} \mathrm{~g}_{4}^{\mathrm{ij}}\left(\mathrm{r}_{\mathrm{ij}}\right)-\frac{\boldsymbol{\mu}_{\mathrm{i}} \cdot \mathbf{r}_{\mathrm{ij}} \mathrm{q}_{\mathrm{j}}}{\mathrm{r}_{\mathrm{ij}}^{3}} \mathrm{~g}_{4} \mathrm{ii}\left(\mathrm{r}_{\mathrm{ij}}\right)+\frac{\boldsymbol{\mu}_{\mathrm{i}} \cdot \boldsymbol{\mu}_{\mathrm{j}}}{\mathrm{r}_{\mathrm{ij}}^{3}}-\frac{3\left(\mathbf{r}_{\mathrm{ij}} \cdot \boldsymbol{\mu}_{\mathrm{i}}\right)\left(\mathbf{r}_{\mathrm{ij}} \cdot \boldsymbol{\mu}_{\mathrm{j}}\right)}{\mathrm{r}_{\mathrm{ij}}^{5}}\right] \\
& +\sum_{\mathrm{i}} \frac{\left|\boldsymbol{\mu}_{\mathrm{i}}\right|^{2}}{2 \alpha^{\mathrm{i}}}
\end{aligned}
$$

where $\alpha^{i}$ is the polarizability of ion $i$ and $\boldsymbol{\mu}_{i}$ and $\boldsymbol{\mu}_{j}$ are the induced dipoles. It takes into account three different contributions: the charge-dipole and the dipole-dipole interactions as well as the energy cost to deform the electronic atomic cloud. $g^{i j}$ is the short-range correction to the multipolar expansion by the Tang-Toennies damping function:

$$
g_{4}^{i j}\left(r_{i j}\right)=1-c_{i j} e^{-b_{D}^{i j} r_{i j}} \sum_{k=0}^{4} \frac{\left(b_{D}^{i j} r_{i j}\right)^{k}}{k !}
$$


The dipoles are calculated at each Molecular Dynamics (MD) simulation step in order to minimize the polarization energy.

\section{Force field parametrization}

Some of the potential parameters are already known:

- Coulombic interaction: it was shown previously from density functional theory (DFT) calculations on pyrophyllite that the Wannier centers, which provide a picture of the electronic density around each nucleus, are all localized around oxygen atoms. As a consequence, formal charges can be attributed to the atoms of the system: -2 for $\mathrm{O},+4$ for $\mathrm{Si},+3$ for $\mathrm{Al}$ and +2 for Mg. Only hydroxyl groups carry partial charges: $\mathrm{O}_{O H}^{(2-\delta)-}$ and $\mathrm{H}_{O H}^{(1-\delta)+}$ in order to take into account the shift of the Wannier center along the $\mathrm{OH}$ bond due to the presence of the dipole. In our previous work the transferred charged was evaluated to: $\delta=+0.8983 .{ }^{43}$

- Dispersion interaction: the parameters of the dispersion term for the cation-oxygen interactions were taken equal to the $\mathrm{X}$-oxygen ones (where $\mathrm{X}=\mathrm{Al}^{3+}, \mathrm{Mg}^{2+}$ or $\mathrm{Si}^{4+}$ ) determined elsewhere. ${ }^{49}$ The dispersion interactions between cations were neglected because they are negligible with respect to the strong electrostatic repulsion.

Morever, in our previous works on dry clays, ${ }^{44}$ we already determined the parameters $A_{i j}, B_{i j}$

of the repulsive potential and $c_{i j}$ and $b_{D}^{i j}$ of the polarizable term, for the interactions between all the montmorillonite atoms and between counterions $\left(\mathrm{Na}^{+}, \mathrm{Cs}^{+}, \mathrm{Ca}^{2+}, \mathrm{Sr}^{2+}\right)$ and montmorillonite atoms. In the case of hydrated montmorillonites, the parameters between water and the rest of the system must be determined.

In 2012, Tazi et al. ${ }^{36}$ parametrized a PIM for aqueous ions. They used the polarizable Dang Chang model for water. ${ }^{50}$ This water model is a rigid four-sites model, with an additional virtual site along the symmetry axis of the molecule which carries the negative partial charge and the induced dipole. This model is represented in Figure 1 and its characteristics are given in Table 1. 
The PIM model was found to reproduce very well the free energies of hydration and the diffusion coefficients of the cations in water. The same water model was used in the present work.

Therefore the only parameters which remain to be parametrized are the repulsion and polarization parameters $A_{i j}, B_{i j}, c_{i j}$ and $b_{D}^{i j}$ between water and the clay atoms. The other parameters are reported in the supporting information. The parametrization of the force field is done by minimizing the error made in the classical calculation of atomic forces and dipoles with respect to DFT calculations. The procedure is not detailed in the present paper but can be found elsewhere. ${ }^{43,44}$

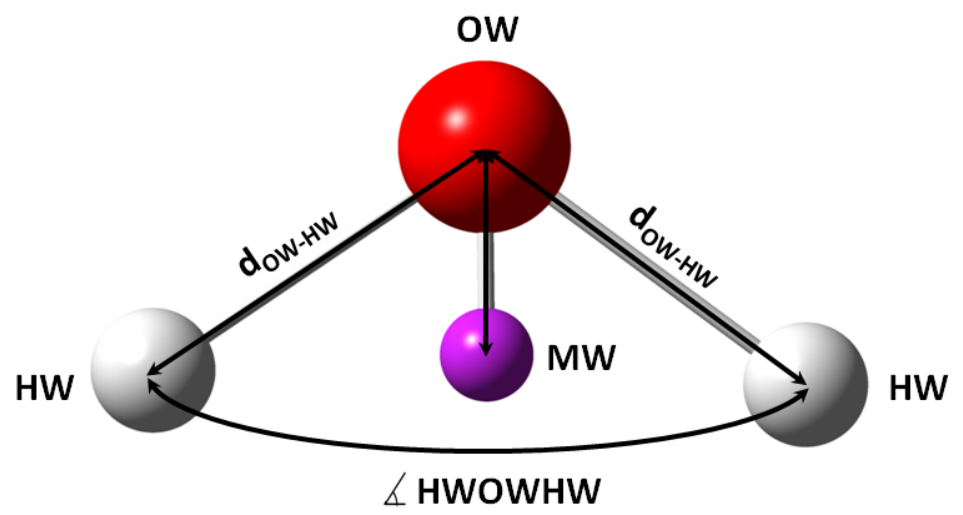

\section{Hydrogen Oxygen Virtual Site}

Figure 1: Structure of the water model.

The montmorillonite simulation boxes used for the parametrization contained two clay layers of lateral dimensions $20.72 \times 17.96 \AA^{2}$, corresponding to 8 unit cells of formula $\mathrm{X}_{0.75 / n} \mathrm{Si}_{8} \mathrm{Al}_{3.25} \mathrm{Mg}_{0.75} \mathrm{O}_{20}(\mathrm{OH})_{4}$

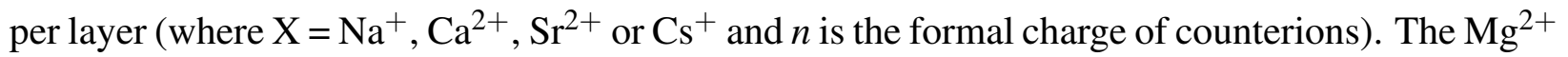
cations were placed randomly in the octahedral sheet, with an exclusion rule preventing two substitutions to be adjacent. The layer-to-layer distances were, respectively, fixed to $12.5 \AA$ and $15.5 \AA$ for the Na-, Ca-, Sr- and Cs-montmorillonites in the monohydrated and the bihydrated state. The number of water molecules per unit cell was, respectively, fixed to 4.5 and 9 in the monohydrated and the bihydrated state.

The interaction parameters between water oxygen atoms OW or the virtual site MW which carries the instantaneous water dipole and the clay atoms were initially taken to be equal to the ones 


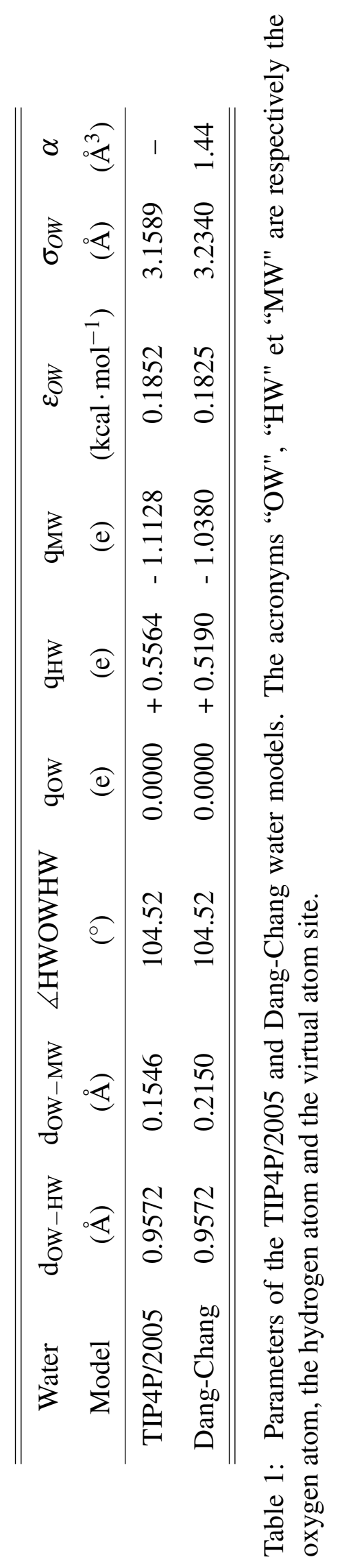


between oxygen atoms of the hydroxyl groups $\mathrm{O}_{O H}$ and other clay atoms. First classical molecular dynamics trajectories were generated with the $\mathrm{CP} 2 \mathrm{~K}$ simulation package. ${ }^{51}$ Periodic boundary conditions were used in the three directions of space. The temperature $T=300 \mathrm{~K}$ was controlled via a Martyna et al. thermostat ${ }^{52}$ with a time constant equal to 1 ps. Electrostatic interactions were computed using dipolar Ewald summation, ${ }^{53,54}$ with a tolerance of $10^{-7}$. The timestep was $0.5 \mathrm{fs}$. After a phase of equilibration of $700 \mathrm{ps}$, three independent equilibrium configurations were sampled from the trajectory separated from each other by $150 \mathrm{ps}$. Then for each counterion, the parametrization of the force field was achieved using $\mathrm{N}_{\text {conf }}=6$ representative configurations per montmorillonite: 3 configurations of $t v$-X-montmorillonite and $3 c v-\mathrm{X}$-montmorillonite configurations with $\mathrm{X}=\mathrm{Na}^{+}, \mathrm{Ca}^{2+}, \mathrm{Sr}^{2+}$ or $\mathrm{Cs}^{+}$. We tried to use more configurations when adjusting the parameters, and we observed that it did not influence further the values of the parameters.

DFT calculations were performed on the same configurations with the $\mathrm{PBE}^{55}$ functional for all the systems. Goedecker-Teter-Hutter ${ }^{56-58}$ pseudopotentials were used with the DZVP planewave basis sets ${ }^{59}$ and an energy cutoff of at least 400 Ry. After determining the ground-state wavefunctions, the forces acting on each atom were computed and the dipoles were calculated from the Maximally Localized Wannier Functions ${ }^{58,60,61}$ (MLWFs). All these calculations were performed with the $\mathrm{CP} 2 \mathrm{~K}$ simulation package. ${ }^{51}$

The numerical minimization of the differences between classical and DFT dipoles and forces were performed with the Minuit library. ${ }^{62}$ During subsequent iterations of the minimization procedure, new configurations used for the dipole- and force-matching were generated using PIM with the current values of these parameters.

\section{Force Field Parameters}

Figure 2 and Figure 3 illustrate the comparison between the forces and the dipoles and for one of the montmorillonite configurations in the bihydrated state, calculated with the classical force field after minimization and from the DFT calculations.

The corresponding error functions, $\chi_{\text {Dipoles }}^{2}$ and $\chi_{\text {Forces }}^{2}$ are shown in Table 2. 
Na-montmorillonite

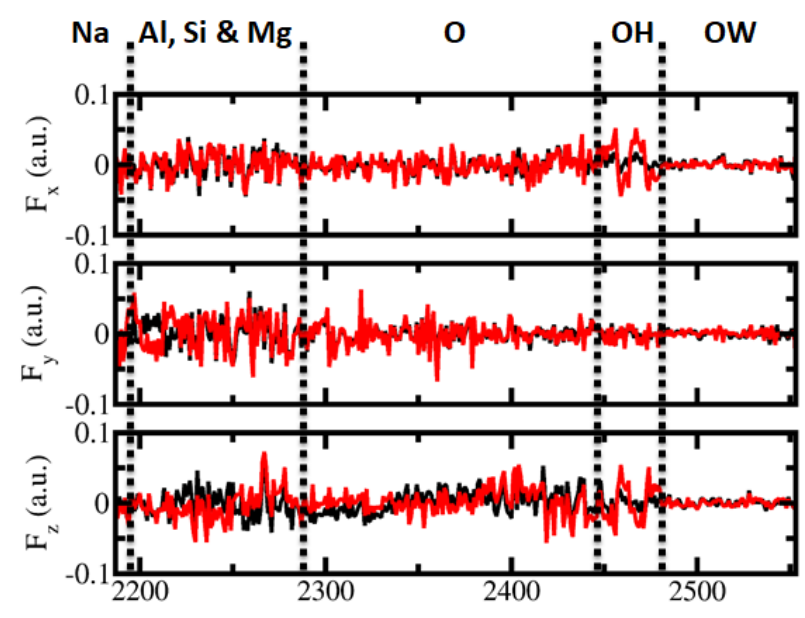

Cs-montmorillonite

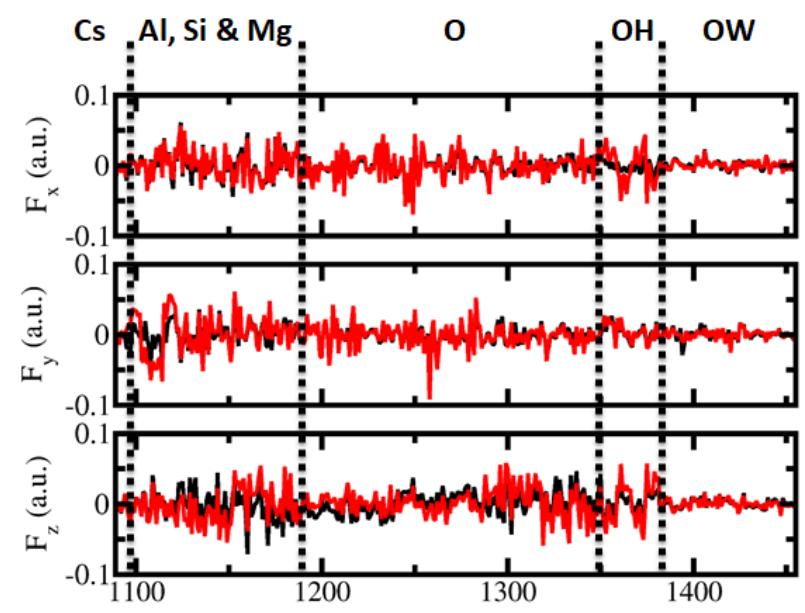

\section{Ca-montmorillonite}

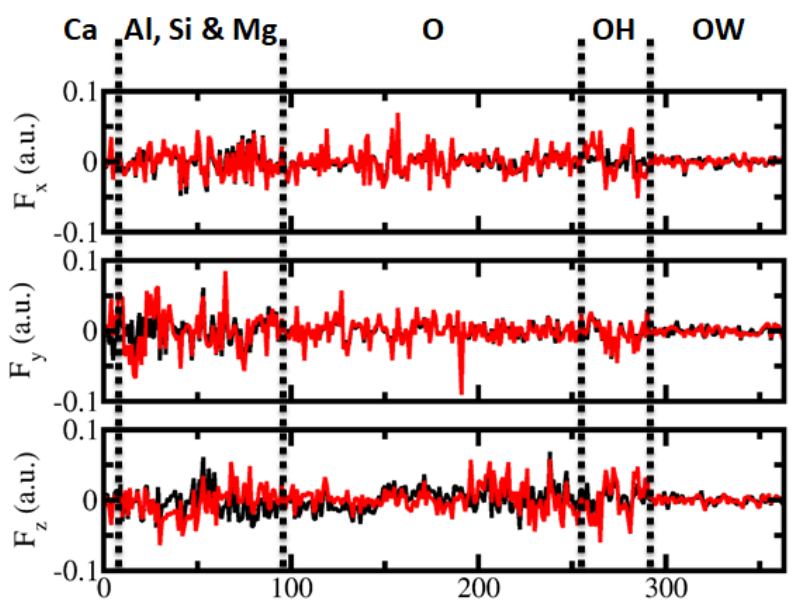

Sr-montmorillonite

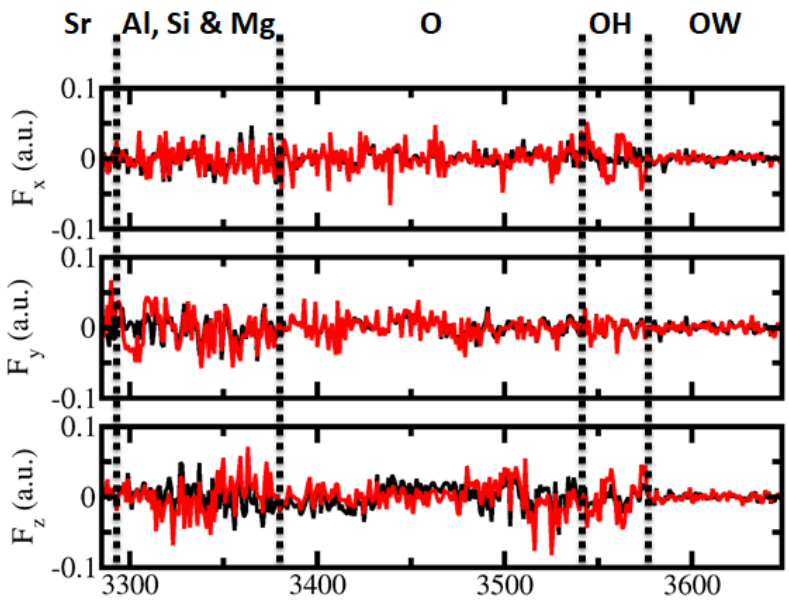

Figure 2: Forces for each atom for one of the montmorillonite configurations in the bihydrated state. The predictions of the classical force field (black lines) for the force components $\left(F_{x}, F_{y}\right.$ and $\mathrm{F}_{\mathrm{z}}$ ) are compared to the DFT results (red lines). The atom indices are grouped by atom types: counterion, cations ( $\mathrm{Al}, \mathrm{Si}, \mathrm{Mg}$ ), clay oxygen atoms $(\mathrm{O})$, clay oxygen atoms in hydroxyl groups $(\mathrm{OH})$, water oxygen atoms. The groups are delimited by the vertical dashed lines.

Table 2: $\chi^{2}$ for the dipoles and the forces for hydrated charged clays.

\begin{tabular}{ccc}
\hline \hline Systems & $\chi_{\text {Dipoles }}^{2}$ & $\chi_{\text {Forces }}^{2}$ \\
\hline Montmorillonite & 0.073 & 1.253 \\
\hline \hline
\end{tabular}


Na-montmorillonite

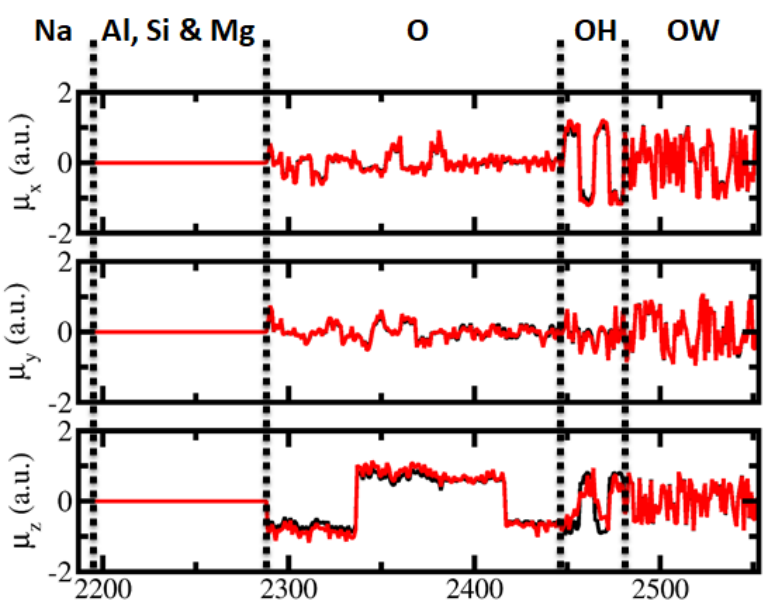

Cs-montmorillonite

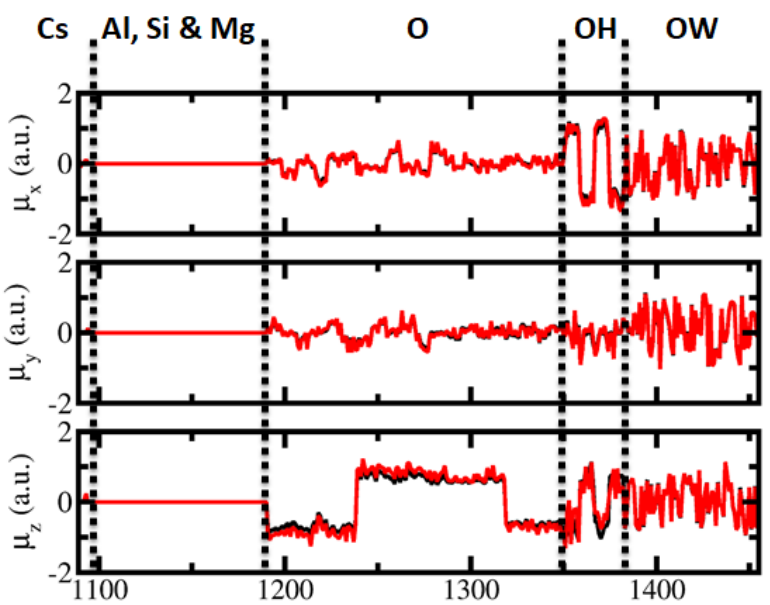

Ca-montmorillonite

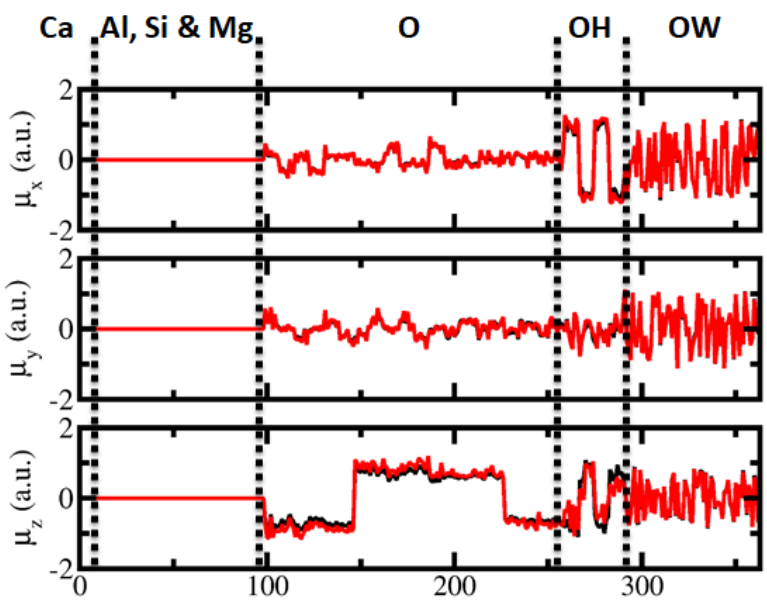

Sr-montmorillonite

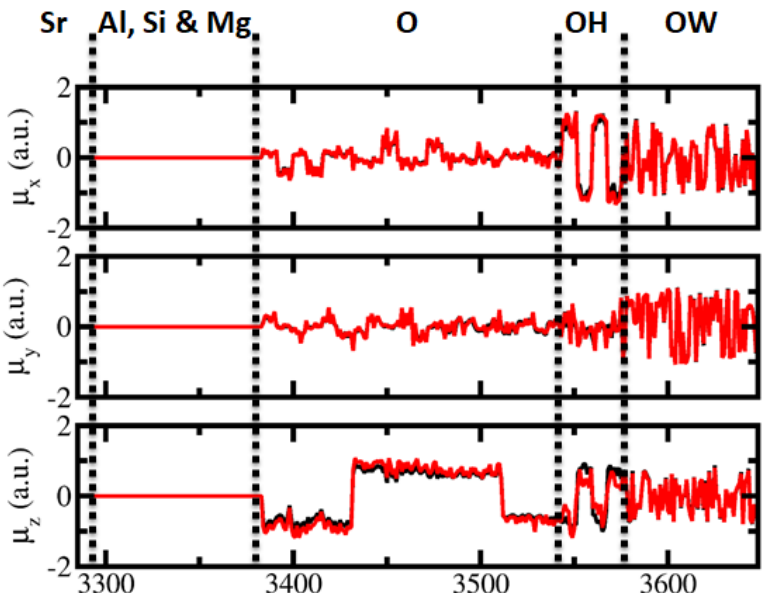

Figure 3: Dipoles for each atom for one of the montmorillonite configurations in the bihydrated state. The predictions of the classical force field (black lines) for the dipole components $\left(\mu_{\mathrm{x}}, \mu_{\mathrm{y}}\right.$ and $\mu_{\mathrm{z}}$ ) are compared to the DFT results (red lines).The atom indices are grouped by atom types: counterion, cations $(\mathrm{Al}, \mathrm{Si}, \mathrm{Mg})$, clay oxygen atoms $(\mathrm{O})$, clay oxygen atoms in hydroxyl groups $(\mathrm{OH})$, water oxygen atoms. The groups are delimited by the vertical dashed lines. 
Most of the errors on the forces come from the forces exerted on the aluminum, silicon, magnesium and apical oxygen atoms. All errors observed on the dipoles come from the oxygen atoms of the hydroxyl groups. $\chi_{\text {Dipoles }}^{2}$ and $\chi_{\text {Forces }}^{2}$ obtained for the hydrated charged clays are larger than those for the neutral clays ${ }^{43}$ and dry charged clays ${ }^{44}$ from previous works. Most of these relative errors are due to very small values of forces and dipoles. All the parameters determined in the present work are summarized in Table 3 and Table 4.

\section{Results and discussion}

In this section, we study structural and dynamical properties obtained with PIM and validate the force field by comparing them with experimental data. In parallel, simulations are performed with the state-of-the-art non-polarizable force field CLAYFF. ${ }^{32}$ CLAYFF has been developed to simulate hydrated and multicomponent minerals (oxides, hydroxides, oxyhydroxides) and their interfaces with aqueous solutions. It is a partial charge model with no bonded interactions except for hydroxyls (like with PIM): it is a fully flexible model which allows for exchange of momentum and energy among all species. It has proved to offer a satisfactory description of these systems and is currently the most used force field among the clay community. In the following, the differences between PIM and CLAYFF results are highlighted.

\section{Simulation details}

Most of the fluid properties were obtained with montmorillonite simulation boxes containing cisand trans-vacant clay layers of lateral dimensions $41.44 \times 35.88 \AA^{2}$, corresponding to 32 unit cells. Layer-to-layer distances of $12.5 \AA$ and $15.5 \AA$ were chosen for all the montmorillonites in the mono- and the bihydrated states, respectively, corresponding to a water content of 4.5 and 9 water molecules per unit cell. These distances and water contents are in the range of the usual experimental values obtained with montmorillonites. ${ }^{63-68}$ Only the monohydrated state was simulated in the case of Cs-montmorillonite since the bihydrated state is not seen experimentally. ${ }^{69}$ 


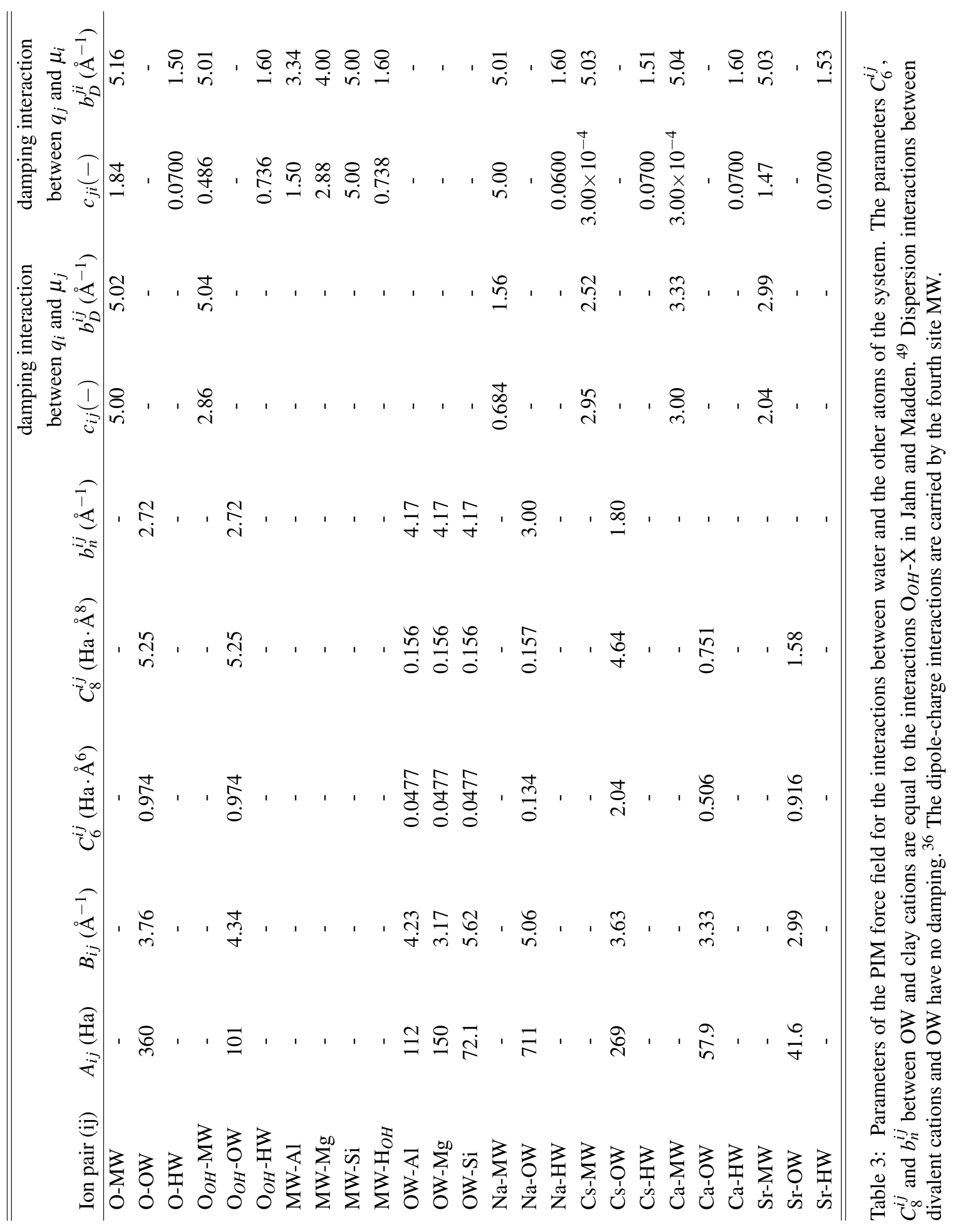


Table 4: Atomic polarizabilities

\begin{tabular}{lccccccc}
\hline \hline species & $\mathrm{O}$ & $\mathrm{OH}$ & $\mathrm{Na}$ & $\mathrm{Cs}$ & $\mathrm{Ca}$ & $\mathrm{Sr}$ & $\mathrm{MW}$ \\
\hline $\begin{array}{l}\text { polarizability } \\
\left(\AA^{3}\right)\end{array}$ & 0.907 & 2.39 & 0.180 & 2.02 & 0.440 & 0.810 & 1.44 \\
\hline \hline
\end{tabular}

In parallel, other simulations were performed for a direct comparison with existing experimental XRD patterns. ${ }^{68}$ Only bihydrated states of montmorillonite were considered as the monohydrated state would not be enough discriminating. ${ }^{23,70}$ For these simulations, a cis-vacant structure of the clay layer was chosen in agreement with the structure of the natural montmorillonite used. ${ }^{71}$ Note, however, that preliminary tests with computed interlayer organization considering transvacant clay layer would lead to similar results. The layer-to-layer distance $h$ was extracted from experimental XRD data. ${ }^{68}$ The dimensions of the simulated clay layers used for this comparison are given in the supporting information.

For simulations with CLAYFF, the TIP4P/2005 model was chosen because it is one of the best models to reproduce bulk water properties, such as the phase diagram or the diffusion coefficients over a large domain of temperatures. ${ }^{72-75}$ The characteristics of this model are reported in Table 1. As in the original CLAYFF model, the Lennard-Jones parameters for the interactions of fluid atoms with surface oxygen atoms were taken to be the same as with water oxygen atoms. The LennardJones parameters for $\mathrm{Na}^{+}, \mathrm{Cs}^{+}$and $\mathrm{Ca}^{2+}$ were taken from the original CLAYFF paper, ${ }^{32}$ the ones for $\mathrm{Sr}^{2+}$ were taken from Ref. 76. Lorentz-Berthelot combination rules were used.

Molecular dynamics simulations were performed in the NVT ensemble with a timestep of 1 fs, starting from realistic configurations obtained with a home made Monte Carlo code. The simulations were performed with $\mathrm{CP} 2 \mathrm{~K} .{ }^{51}$ The temperature, $T=300 \mathrm{~K}$, was controlled by an extension of the Nosé-Hoover thermostat developed by Martyna et al $^{52}$ with a time constant equal to 1 ps. Electrostatic interactions were computed using dipolar Ewald summation, ${ }^{53,54}$ with a tolerance of $10^{-7}$. Trajectories over 1 ns were generated but averaged atomic density profiles and diffusion coefficients were extracted from the last 500 ps only. Diffusion coefficients parallel to the 
clay layers were calculated from the slope of the parallel mean-squared displacement as a function of time in the time region [50-250] ps for water and [50-150] ps for counterions.

\section{Interlayer structure}

We now proceed to the validation of the new PIM force field against existing XRD data on natural cis-vacant- Na-, Ca- and Sr-montmorillonites. ${ }^{67,68}$ Both XRD and molecular simulations probe the organization of matter at the same length scale and their combination has been shown to provide discriminating constraints on the simulated interlayer organization and associated force field used to model clay-water interaction. ${ }^{23,70,77}$

Comparison between experimental and generated XRD profiles using either PIM or CLAYFF is performed on the basis of existing XRD calculation routine (see ref. 68 for details) and the methodology detailed in Ferrage. ${ }^{77}$ In short, the interlayer atomic density profiles derived from simulations are divided into a series of individual atomic planes (separated by distance of $\sim 0.05 \AA$ along $h$ ) containing $\mathrm{O}, \mathrm{H}$, or cation $\left(\mathrm{Na}^{+}, \mathrm{Ca}^{2+}\right.$, or $\left.\mathrm{Sr}^{2+}\right)$ as neutral atoms with no additional positional disorder related to temperature. The XRD pattern for $00 l$ reflections is then generated and compared to experimental data. The comparison between experimental and calculated profiles in Figure 4 shows that a fair agreement for the whole $00 \mathrm{l}$ reflections series is obtained using PIM. When using CLAYFF, even though a satisfactory fit is received for Ca-montmorillonite, noticeable misfits are noticed for other samples. These misfits mainly concern the 002, 003, and 005 reflections for $\mathrm{Na}$ - and $\mathrm{Sr}$-montmorillonite. As previously shown for bihydrated smectites, these reflections are highly sensitive to the z-position of the oxygen atoms. ${ }^{23,68}$ For instance, Ferrage et al. ${ }^{23}$ showed that by slightly repelling water molecules from the clay surface it was possible to obtain a better reproduction of experimental intensities of $00 \mathrm{l}$ reflections.

A similar enhanced repulsion of water molecules from the clay surface when using PIM compared to CLAYFF model is observed on all the atomic distributions. It is illustrated on Figure 5 in the case of the bihydrated $c v$-Na-montmorillonite: with PIM the main distribution peaks are located at $6.5 \AA$ from the center of their adjacent clay layer, further than the peaks obtained with 


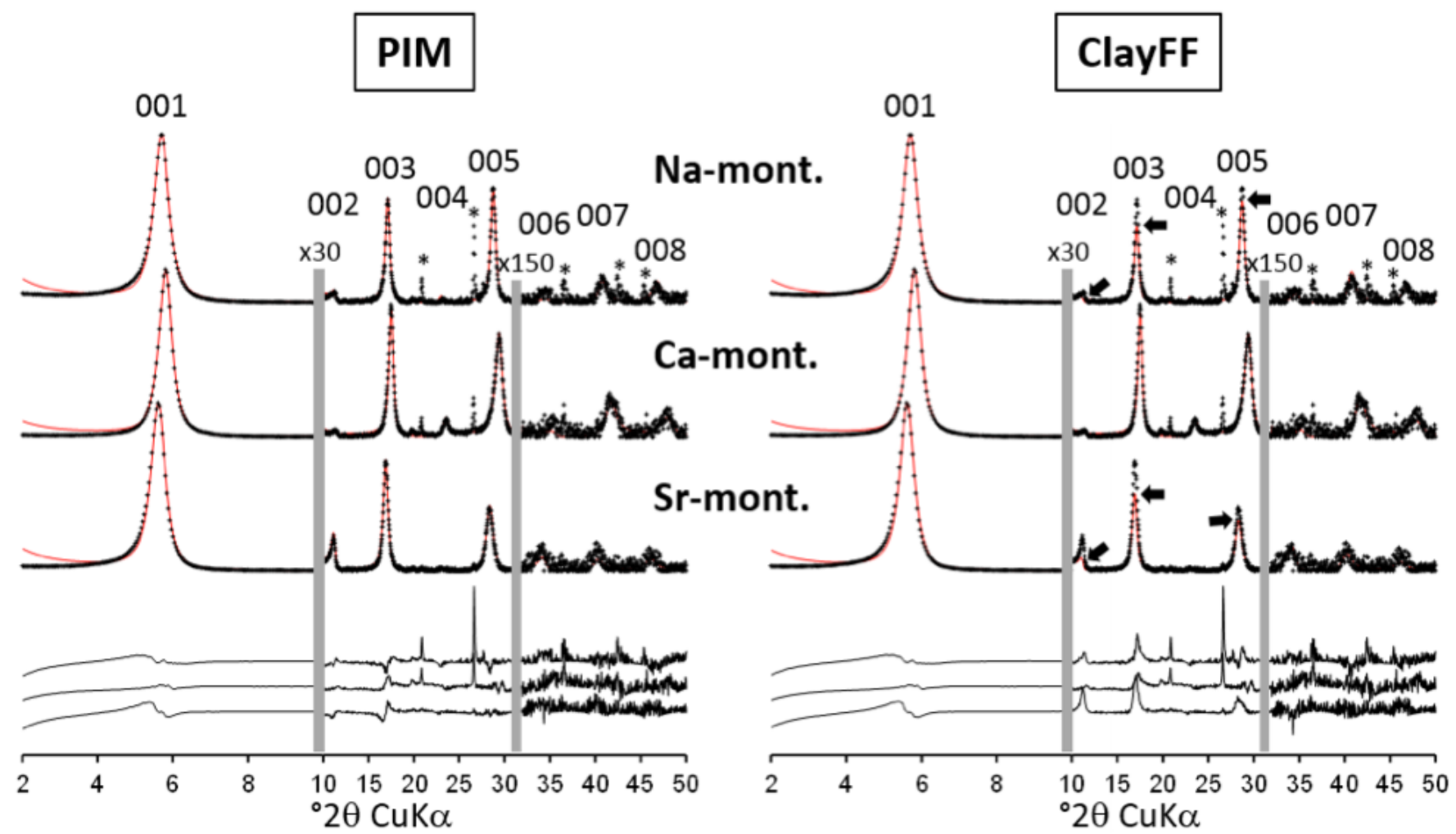

Figure 4: Experimental (black crosses) ${ }^{68}$ and calculated (red lines) intensities of $00 l$ reflections for Na-, Ca-, and Sr-montmorillonite using PIM (left) or CLAYFF (right) models. Presence of accessory quartz reflections is indicated by a *. Difference plots are shown at the bottom of the figure. The vertical gray bars indicate a modified scale factor for the high-angle regions as compared to the low-angle part of the patterns. Solid arrows indicate a significant misfit between experimental and calculated patterns. $00 \mathrm{l}$ reflections are indexed on the top part of the figure. 
CLAYFF, located at a distance of $6.1 \AA$. This property is likely at the origin of the better agreement with experiments obtained with PIM. This comparison between simulation and experimental diffraction method thus provides evidences that PIM model allows for a satisfactorily reproduction of interlayer organizational properties of water and cations.

PIM

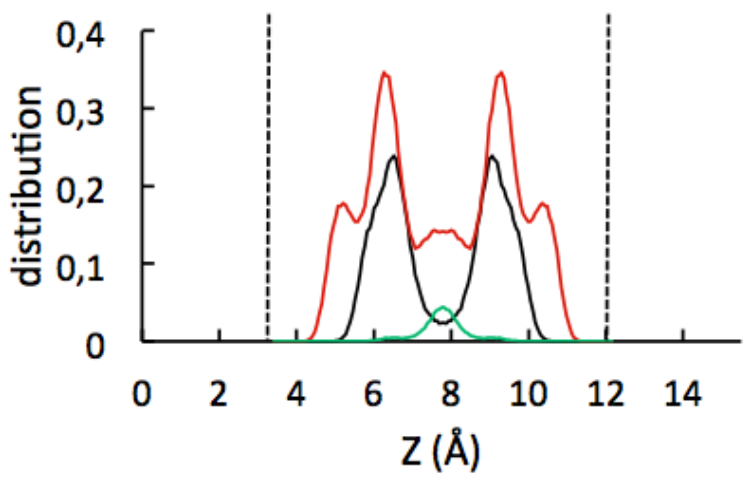

clayFF

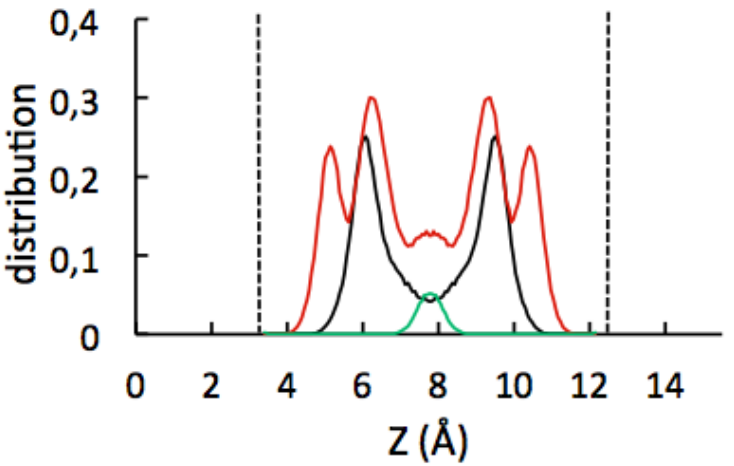

Figure 5: Atomic distributions in the direction perpendicular to the clay layer in bihydrated Namontmorillonites. The red, black and green curves are respectively the atomic distribution of the water molecule hydrogen atoms, the water molecule oxygen atoms and the sodium cations.

In bihydrated states, the atomic distributions show that the cations are fully hydrated. However, when comparing PIM and CLAYFF in more detail, we observe that the localization of the cations with respect to the surfaces differs in the monohydrated states. As it can been seen on the sodium distributions of Figure 6a, Figure 6b, Figure 6c, and Figure 6d the presence of two peaks in the case of CLAYFF (instead of one in the case of PIM) comes from the fact that sodium cations come slightly closer to the surface in the case of CLAYFF. This is also observed on the radial distribution function $\mathrm{g}_{\mathrm{Na}-\mathrm{O}_{S}}(r)$ given on Figure 7 which shows a small peak on the CLAYFF $\mathrm{g}_{\mathrm{Na}-\mathrm{O}_{S}}(r)$ at a distance of $2.5 \AA$, which is not present with PIM. Let us note however that at a distance of $3.4 \AA$ from the cation, which can be considered as the first hydration shell radius, the global number of surface oxygen atoms surrounding the cations is the same as seen on coordination number curves. In fact, Figure 8 shows that the cations exhibit rather different diffusion mechanisms along the surfaces: $\mathrm{Na}^{+}$remain above hexagonal cavities with PIM whereas they diffuse closer to surface oxygen atoms with CLAYFF. 

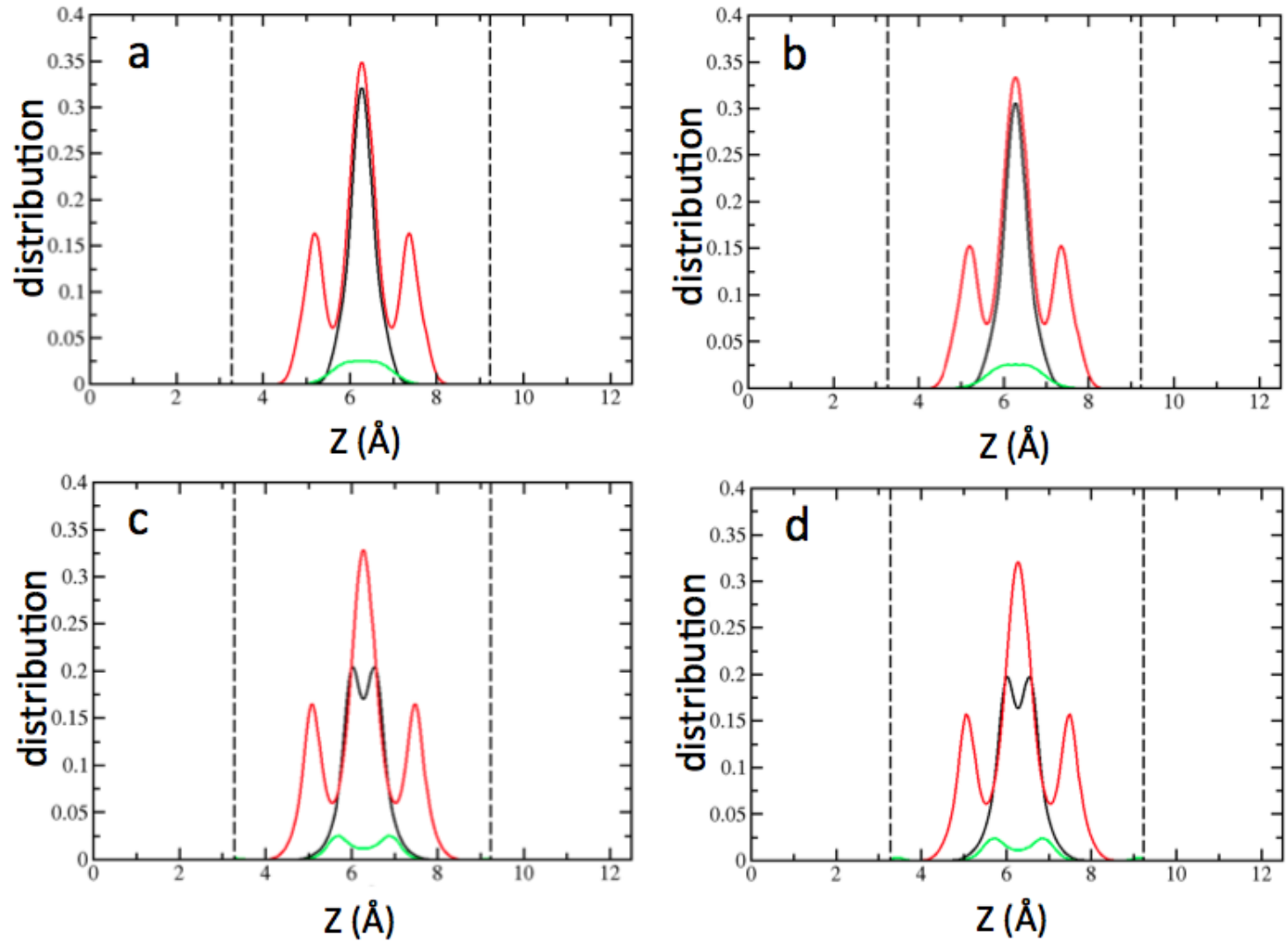

Figure 6: Atomic distributions in the direction perpendicular to the clay layer in monohydrated Na-montmorillonites. The graph $\mathrm{a}$ and $\mathrm{b}$ are obtained with the PIM force field. The graph $\mathrm{c}$ and $\mathrm{d}$ are obtained with the CLAYFF force field. The graph a and $\mathrm{c}$ are obtained with a $c v-\mathrm{Na}-$ montmorillonite. The graph $\mathrm{b}$ and $\mathrm{d}$ are obtained with a $t v$-Na-montmorillonites. The red, black and green curves are respectively the atomic distribution of the water molecule hydrogen atoms, the water molecule oxygen atoms and the sodium cations. 

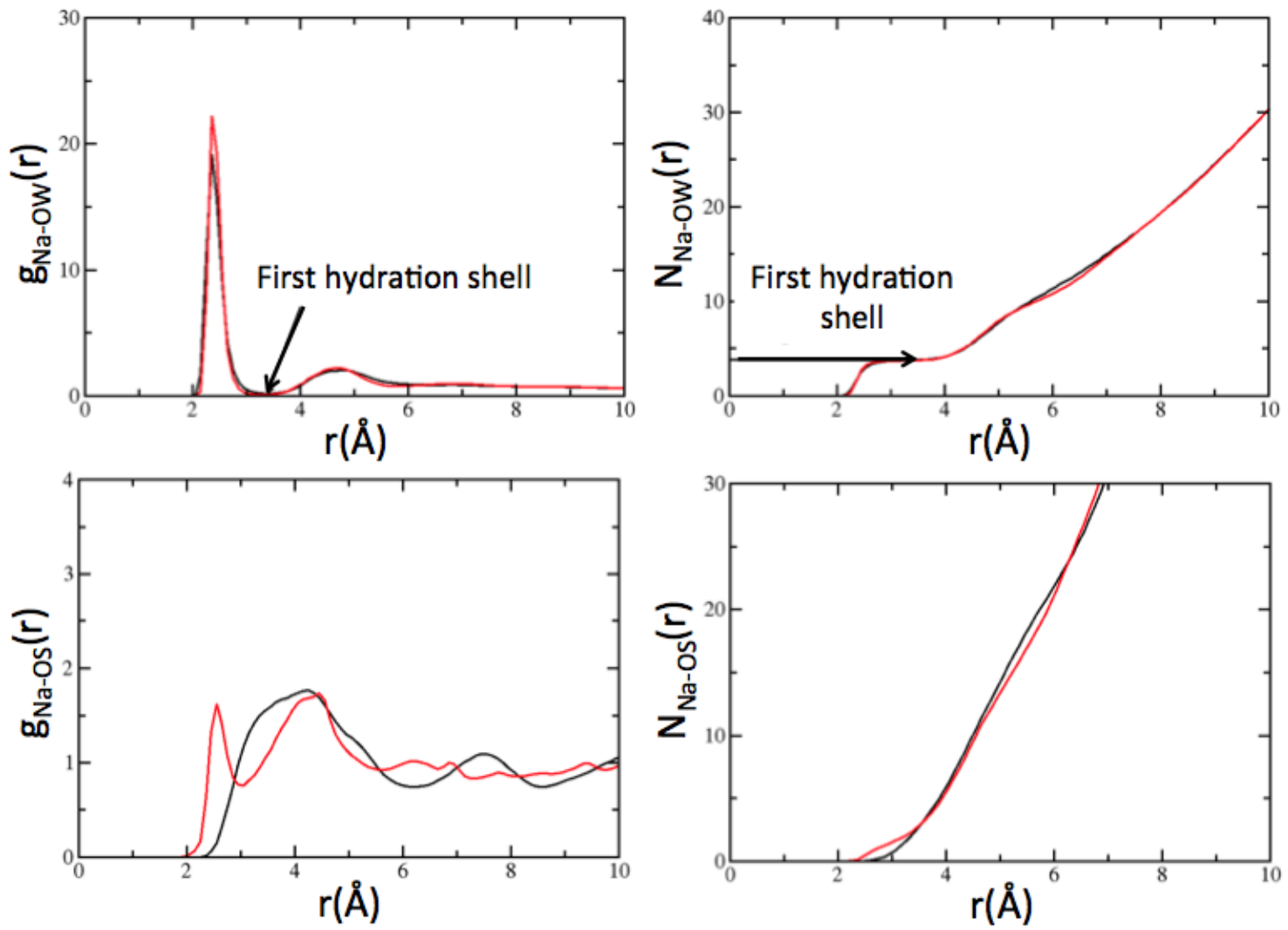

Figure 7: Cation-oxygen radial distribution functions and coordination numbers in monohydrated Na-montmorillonite. OW and OS atoms are, respectively, the water and the surface oxygen atoms. The black and red curves were, respectively, obtained with PIM and CLAYFF force fields. 
PIM
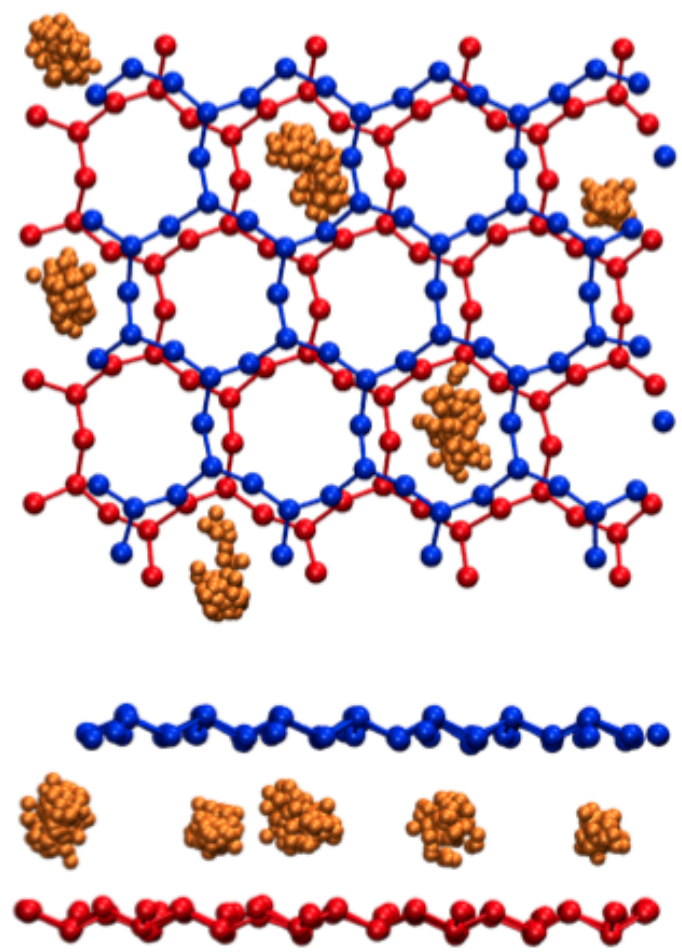

clayFF
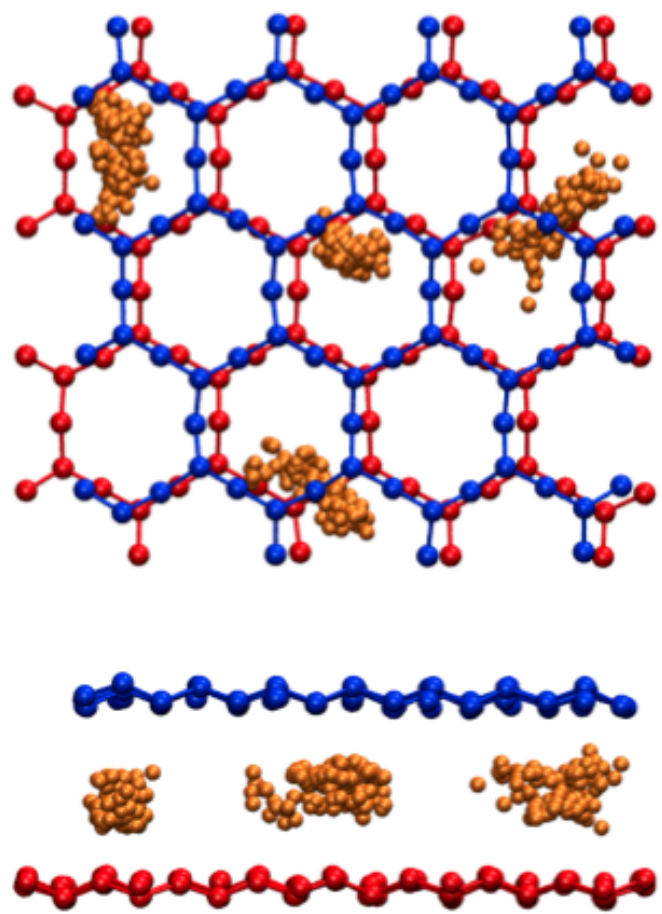

Figure 8: Snapshots obtained in monohydrated Na-montmorillonites with PIM and CLAYFF. Only surface silicium and oxygen atoms are represented. Red and blue atoms differentiate the two opposite surfaces. The orange atoms show Na trajectories over some picoseconds. During this period, clay layer atoms vibrate around their equilibrium position but the layer remain globally fixed. For the sake of clarity only one configuration of the clay layers is represented. 
Similar remarks can be done on montmorillonites compensated with divalent cations (see Figure 9a, Figure 9b, Figure 9c, and Figure 9d for Sr-montmorillonite in the monohydrated state; The results obtained with $\mathrm{Ca}^{2+}$ lead to the same conclusions and are provided in the supporting information). In this case however, two small peaks on each side of the OW distribution are observed in the case of CLAYFF, besides the splitting of the cation distribution: A water molecule can come and hydrate the cation by being located in between the cation and the opposite surface. This is confirmed by the radial distribution functions (see Figure 10) which show that there are more water molecules in the first hydration shell of the cation with CLAYFF than with PIM.
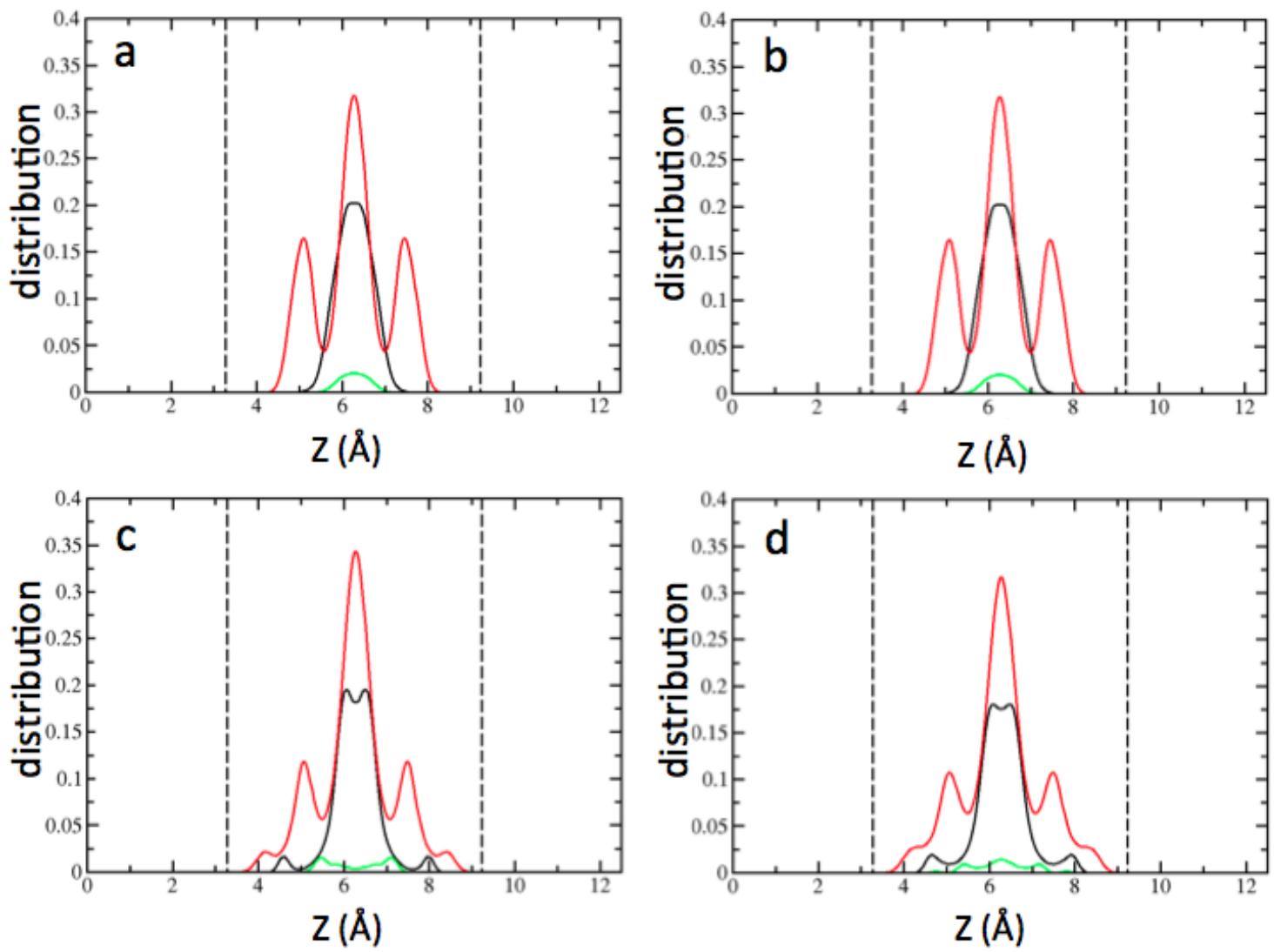

Figure 9: Atomic distributions in the direction perpendicular to the clay layer in monohydrated Sr-montmorillonites. Panels a and b (resp. c and d) are obtained with the PIM (resp. CLAYFF) force field. Panels a and c (resp. b and d) correspond to $c v$-Sr-montmorillonite (resp. $t v$-Srmontmorillonites). The red, black and green curves are respectively the atomic distribution of the water molecule hydrogen atoms, the water molecule oxygen atoms and the strontium cations.

Let us note that the structural differences between the two force fields are much less pronounced 

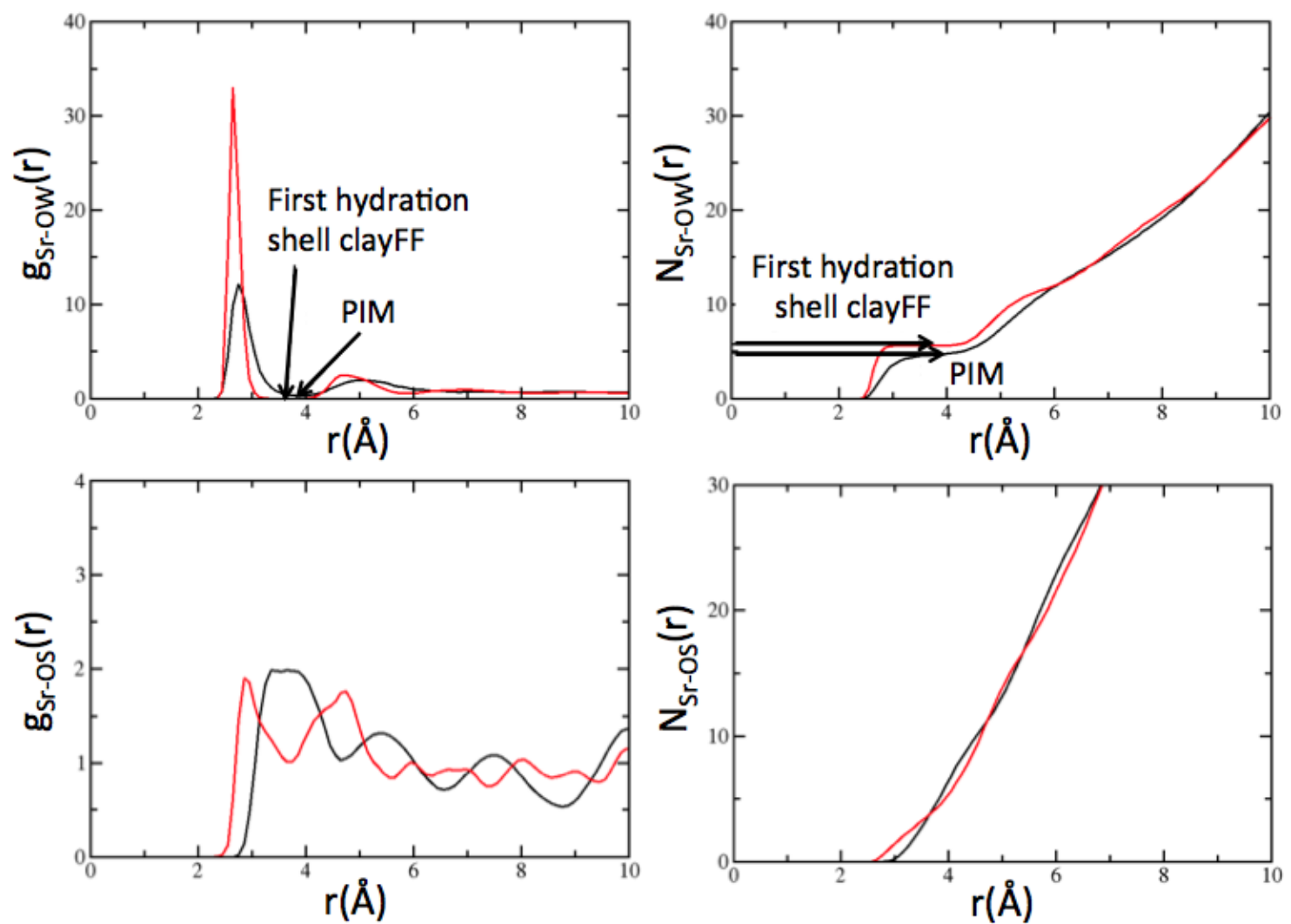

Figure 10: Cation-oxygen radial distribution functions and coordination numbers in monohydrated Sr-montmorillonite. OW and OS atoms are, respectively, the water and the surface oxygen atoms. The black and red curves were, respectively, obtained with PIM and CLAYFF force fields. 
in the case of monohydrated $c v$-Cs-montmorillonite (see supporting information). It may be surprising that a non-polarizable force field and a polarizable one lead to similar properties despite the rather large value of $\mathrm{Cs}^{+}$polarizability. However, in the monohydrated state, $\mathrm{Cs}^{+}$is very confined in the center of the interlayer space, therefore symmetrically influenced by the surfaces. The role of induced dipoles could be much more important when studying the behavior of $\mathrm{Cs}^{+}$in contact with one surface only, as it is the case in interparticle pores. Finally, very little differences are seen between the trans and cis organization of the clay layers. This is also true for the dynamics (see next section). This is not surprising considering the subtle influence that can have the location of the hydroxyl groups on the siloxane surface in direct contact with the fluid.

\section{Interlayer dynamics}

Simulated diffusion coefficients $D$ are reported in Table 5 and Table 6, together with experimental values of water diffusion coefficients obtained with QuasiElastic Neutron Scattering techniques (QENS) and coming from other simulation works of the literature. The experimental values depend on the QENS technique and on the model used to fit the data. For example, in the case of natural montmorillonites, interstratification occurs, which means that several hydrated states are measured at the same time, and water is also present between clay particles. As a consequence, the reported diffusion coefficients are averages over several types of water. Moreover the resolution of the Time-Of-Flight (TOF) apparatus can hide the slowest water molecules ${ }^{78}$ and then overestimate the dynamics. That is why the diffusion coefficients obtained with Neutron Spin Echo (NSE) and time-of-flight on the same samples can differ. ${ }^{78,79}$

Discrepancies in computed $D$ values are noticed between the different force fields used but also between simulations based on the same force field (see Table 6). In particular diffusion coefficients

can be very sensitive to layer-to-layer distances and water contents used in the simulation, ${ }^{22,84,95}$ but also to the layer charge and its distribution (random or well-ordered). Moreover, diffusion coefficients can be calculated from 3D or 2D mean-squared displacements (MSD). The analysis of 3D mean-squared displacements is complicated by the fact that the displacement is bounded 
Table 5: Diffusion coefficient values of cations for the mononhydrated (mono) and bihydrated (bi) montmorillonites. The value of the diffusion coefficients is given in $\times 10^{-10} \mathrm{~m}^{2} \cdot \mathrm{s}^{-1}$. The standard deviation is calculated from the average error per block method. ${ }^{80,81}$ The standard deviation (in parenthesis) applies to the last digit of diffusion coefficients values.

\begin{tabular}{ccccc}
\hline \hline Counterion & \multicolumn{2}{c}{ Values PIM } & \multicolumn{2}{c}{ Values CLAYFF } \\
Hydration state & $t v$-Mmt & $c v$-Mmt & $t v$-Mmt & $c v$-Mmt \\
\hline $\mathrm{Na}^{+}$mono & $0.6(3)$ & $0.6(2)$ & $1.4(9)$ & $1.1(7)$ \\
\hline $\mathrm{Ca}^{2+}$ mono & $0.4(3)$ & $0.4(3)$ & $0.3(2)$ & $0.3(1)$ \\
\hline $\mathrm{Sr}^{2+}$ mono & $0.3(3)$ & $0.4(2)$ & $0.3(1)$ & $0.4(2)$ \\
\hline $\mathrm{Cs}^{+}$mono & $0.08(6)$ & $0.09(4)$ & $0.3(3)$ & $0.3(3)$ \\
\hline $\mathrm{Na}^{+}$bi & $2.8(5)$ & $2.6(3)$ & $2.6(2)$ & $2.4(1)$ \\
\hline $\mathrm{Ca}^{2+} \mathrm{bi}$ & $0.8(6)$ & $0.6(4)$ & $0.5(4)$ & $0.4(2)$ \\
\hline $\mathrm{Sr}^{2+} \mathrm{bi}$ & $0.6(6)$ & $0.3(3)$ & $0.7(3)$ & $0.3(2)$ \\
\hline \hline
\end{tabular}

along the direction perpendicular to the clay layers: At short times, the diffusion can be seen as three dimensional, but the perpendicular mean-squared displacement tends to a constant when time increases, leading to a global two dimensional diffusion. As a consequence the evolution of the 3D mean-squared displacement is not linear: Calculating the diffusion coefficient from a slope taken at small times leads to higher values of $D$ than from a slope taken at higher times. In the monohydrated state, however, the perpendicular diffusion is rapidly bounded because of the strong confinement, and the obtained 3D diffusion coefficient taken from the slope of the 3D MSD can be viewed as equal to $2 / 3$ of the $2 \mathrm{D}$ diffusion coefficient along the clay layers. This is also the case with experimental values which are obtained with randomly oriented powder samples and then are averaged over all directions.

We first note that the PIM force field gives diffusion coefficients in the range of the $D$ values given by previous simulation works. As in previous works, no correction was applied to account for the finite size of the simulation box because in this case it was shown to have a very small influence of diffusion coefficient, ${ }^{84}$ contrary to bulk water simulations. ${ }^{75,96,97}$ Indeed the presence 


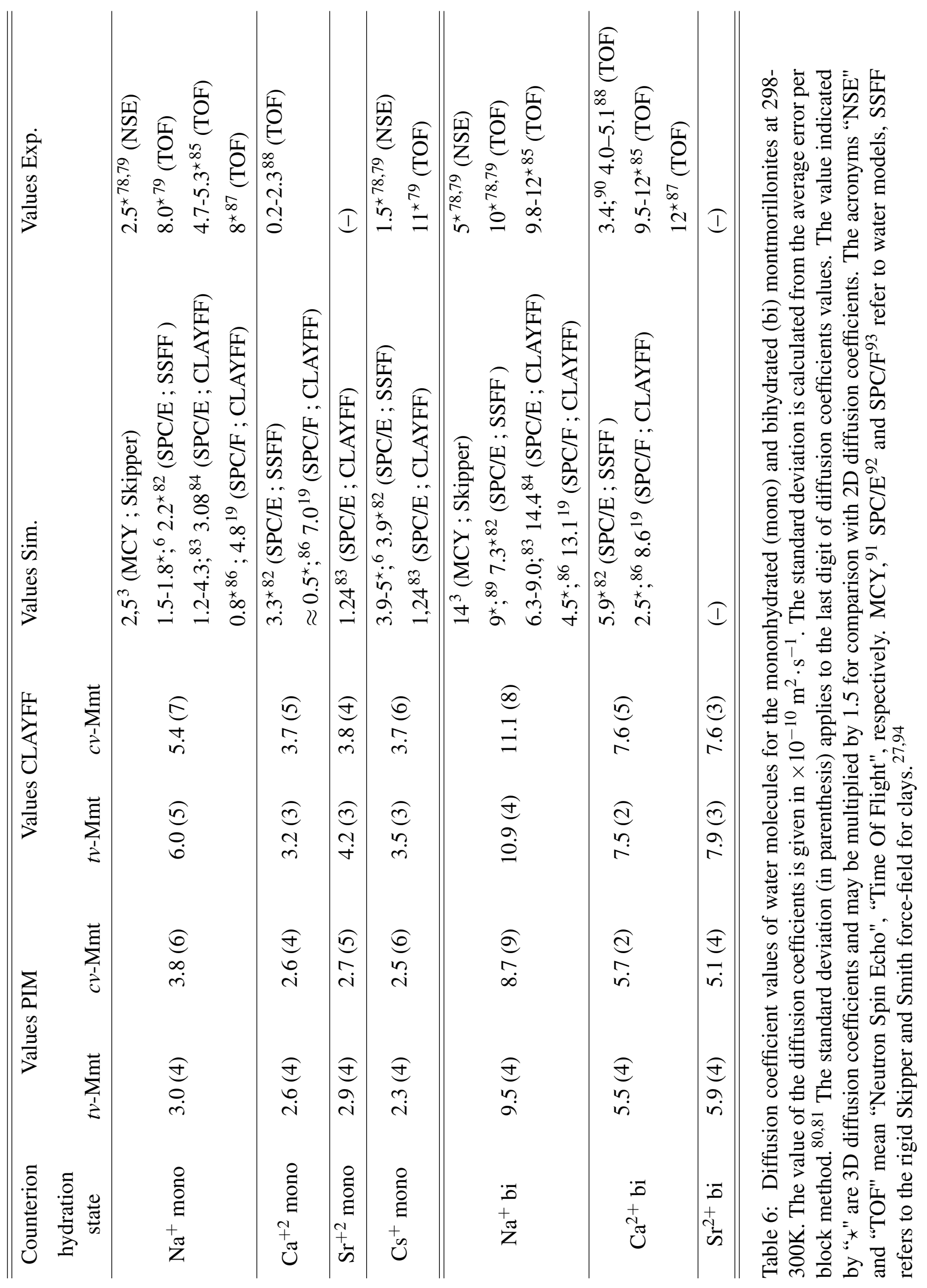


of the confinement leads to different corrections to apply to $D$ compared to the bulk conditions. ${ }^{98}$ Taking the lowest experimental values of diffusion coefficients as the most realistic for the reasons explained above, experimental water diffusion coefficients parallel to the clay layers are in the range $2-4 \times 10^{-10} \mathrm{~m}^{2} \cdot \mathrm{s}^{-1}$ and $5-7.5 \times 10^{-10} \mathrm{~m}^{2} \cdot \mathrm{s}^{-1}$ in the mono- and bihydrated states, respectively. The PIM force field is then in good agreement with experiments, except for the bihydrated Na-montmorillonite, for which it slightly overestimates the diffusion coefficients (by 20\%).

In all cases however, CLAYFF with the TIP4P/2005 model gives always larger water diffusion coefficient than PIM, although in the bulk the Dang-Chang model has a bulk diffusion coefficient about 10\% larger than TIP4P/2005. ${ }^{75}$ The differences between PIM and CLAYFF are even more pronounced in the monohydrated state. Indeed, the water dynamics may be more influenced by the presence of the surfaces in the case of PIM than in the case of CLAYFF, because of a larger surface roughness due to the deformation of the hexagonal cavities and/or because water molecules are more repelled from the surface, and then diffuse in a more confined space. The influence of the cation on water dynamics is also important: In monohydrated Na-montmorillonite for example, the slowing down of the mobile species from CLAYFF to PIM is the same for $\mathrm{Na}^{+}$and water (factor of 2), although it is less important for water (factor of 1.5) than for the cations (factor of 3 ) in the case of Cs-montmorillonite. It can be explained by the fact that in the monohydrated state, almost all the water molecules are localized in the first hydration shell of the cations, but $\mathrm{Cs}^{+}$being less strongly hydrated than $\mathrm{Na}^{+}$, water molecules are less influenced by their interactions with $\mathrm{Cs}^{+}$ than with $\mathrm{Na}^{+}$.

In the case of montmorillonite compensated with divalent cations, the diffusion coefficients of the cations are similar for both force fields in the two hydrated states. In both states however, water molecules diffuse about $40 \%$ more slowly with PIM than with CLAYFF. Contrary to monovalent cations and despite the strong hydration of divalent cations, part of the water molecules is not involved in the hydration shells of the cations because the number of cations is divided by two. As a consequence, this slowing down can be attributed to a stronger interaction between water and the surfaces in the case of PIM, even stronger than in Na-montmorillonite. 
To conclude, the differences observed between the force fields can have several reasons, which can have a physical origin, such as the role of the polarizability or the deformation of the cavities, or can come from the force field parameters, just as differences can also be observed between two non-polarizable force fields. In order to discriminate, systematic studies with different force fields can be imagined: for example, the use of CLAYFF with and without constrained deformed cavities could help to elucidate the influence of the surface rugosity and the size of the hexagonal cavities on fluid properties.

\section{Transferability of PIM force field towards zeolites}

Unlike two-dimensional phyllosilicates such as clays, zeolites display a three-dimensional framework, consisting only of tetrahedral units, with a diversity of topologies for their assembly. ${ }^{99}$ Subsitutions of $\mathrm{Si}^{4+}$ by $\mathrm{Al}^{3+}$ ions result as for clays in a negative charge compensated by counterions. Multivalent counterions may deform locally the mineral framework, which in turn impacts the distribution of the cations among the crystallographic sites where they can reside. In our previous study, we had shown the transferability of the PIM developed for dry charged clays to the case of zeolites, provided that the parameters used to describe tetrahedral $\mathrm{Al}^{3+}$ in zeolite were taken as those of the tetrahedral $\mathrm{Si}^{4+}$ in clays (except, of course, for the formal charge). Specifically, for dry Na X- and Y-faujasite (which differ by their Al/Si ratio) as well as Ca- and Sr-exchanged faujasites, the PIM satisfactorily predicted the framework structure and the distribution of the extraframework cations among the various cationic sites.

The development of a classical force fields able to accurately describe the flexibility of the framework ${ }^{100}$ is of particular relevance to capture the ion-induced deformation of the framework since standard force fields typically consider the latter as rigid. ${ }^{29,33,101-104}$ This implies in addition the knowledge of the structure from prior experiments. As a further test of the transferability of the PIM to zeolites, we consider here the distribution of extra-framework cations in hydrated $\mathrm{Na}_{58} \mathrm{Y}$ faujasite. Faujasite (FAU) is one of the most widely studied zeolite types, ${ }^{99}$ with well-known crystal structure and corresponding cationic sites, even though the precise position and occupancy 
of these sites can differ depending on the cations nature and content. ${ }^{105}$

\section{Simulation Details}

The cubic simulation box contained one unit cell (space group $\mathrm{Fd} 3 \mathrm{~m}$ ) of composition $\mathrm{Na}_{58} \mathrm{Si}_{134} \mathrm{Al}_{58} \mathrm{O}_{384}$ (see Figure 11), corresponding to a $\mathrm{Si} / \mathrm{Al}$ ratio of 2.3. The distribution of susbstitutions complied with Loewenstein's rule (-Al-O-Al- sequences are prohibited) and random location since it was shown that there is no preferential T-sites in faujasite zeolite. ${ }^{106}$ Simulations were performed in the $N V T$ ensemble with a box size of $24.679 \AA$, corresponding to the (experimental) unit cell at $20^{\circ} \mathrm{C}$. Initial configurations with the desired number of water molecules were first generated at $700 \mathrm{~K}$, using Monte Carlo simulation with the non-polarizable force field of Jaramillo et al. ${ }^{29}$ as described in Ref. ${ }^{101}$ Then, we used these initial configurations (at least two configurations per system to check that the final results were independent of the initial configuration) for molecular dynamics simulations with the PIM force field, equilibrating the system via simulated annealing. Starting from $300 \mathrm{~K}$, we progressively increased the temperature in steps at 500, 700 and $1000 \mathrm{~K}$ to decorrelate the microscopic configuration, in particular the cation distribution, from the initial state. For each step, 100 ps of dynamics were performed and the cation distribution was monitored for the last 50 ps. After heating, the same steps were followed to bring the system back to $300 \mathrm{~K}$, at which the equilibrium cation distributions were sampled. Molecular dynamics simulations with the PIM force field were performed using the CP2K package, using a time step of $0.5 \mathrm{fs}$ and a Nose-Hoover thermostat chain with a time constant of $100 \mathrm{fs}$.

\section{Distribution of Extraframework Cations}

The extraframework cations may be found in various sites, indicated in Figure 11a. The faujasite structure used for molecular simulations is represented in Figure 11b. The description of the different sites (labelled I, I', II, II' or III) can be found elsewhere, e.g. in our previous work on PIM

in the dehydrated case. ${ }^{44}$ In order to assign a given cation to a type of site, we use a new method that we introduced recently. ${ }^{101}$ Contrary to standard approaches, which require the knowledge of 

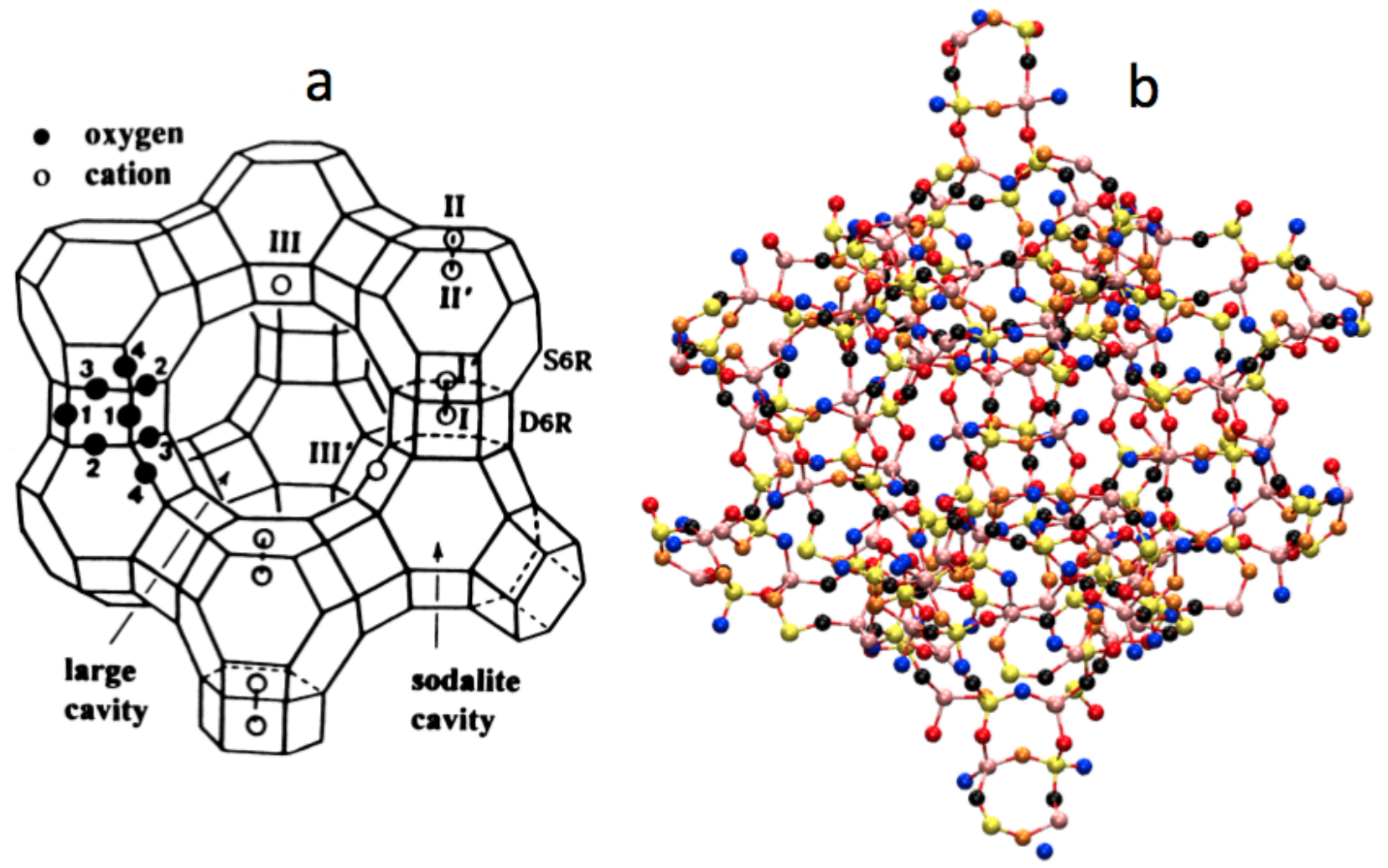

Figure 11: a) Framework structure of faujasite zeolites. ${ }^{107}$ There are 4 nonequivalent oxygen atom types. Extraframework cationic sites are labelled I, I', II, II' and III. b) Snapshot of faujasite structure used for molecular simulations. ${ }^{44}$ 
the precise location of the crystallographic sites from experiments, this method also applies to the case of flexible structures, as it is based on the local environment of the cation (coordination by the different types of oxygen atoms, see Figure 11a).

Our objective is not to discuss in detail the migration of cations between the various sites during the hydration process, but rather to compare the predictions of the PIM force field to the experimental results. The experimental localization of cations as a function of water content is a challenging task. We compare our simulation results for $\mathrm{Na}_{58} \mathrm{Y}$ faujasite to those from a recent neutron diffraction study which allowed to jointly quantify the water content and the cation distribution among the various sites. ${ }^{101}$ For highly hydrated states with a number of water molecules per unit cell $N_{w}>100$, the experimental literature (Refs. ${ }^{108-112}$ ) reports results which are not in quantitative agreement with each other. This may be due to several factors such as the sample preparation or the difficulty to localize cations in the presence of water, in particular low symmetry sites (III, III'), which explains that the sum over all sites is not equal to the total number of cations per unit cell. In addition, the exact water content is not known accurately. While such a disagreement within the experimental literature does not allow a quantitative validation of the PIM in this regime, we still compare our simulation results to the range of reported values.

Figure 12 reports the number of cations per unit cell in the various sites (I, I', II and III) as a function of the number of water molecules per unit cell, $N_{w}$. For each site, we compare the present simulation results with the PIM, also summarized in Table 7, to the experimental results of Ref., ${ }^{101}$ as well as the simulation results of the same reference using a non-polarizable force field and a rigid framework. While the agreement with the experiments is not quantitative for all water contents, the PIM results are within $50 \%$ of the experimental value and display the same trends with increasing $N_{w}$. The values for the largest water content fall within the range of experimental values for all sites. ${ }^{108-112}$ This shows that the present PIM developed for hydrated clays is transferable to faujasite zeolites, with the same slight modification introduced for dry zeolites, namely using the short-range parameters of silicon for tetrahedral aluminum. Beyond the mere transferability of the PIM to zeolites, the present work, shows that it provides a significant improvement for the 


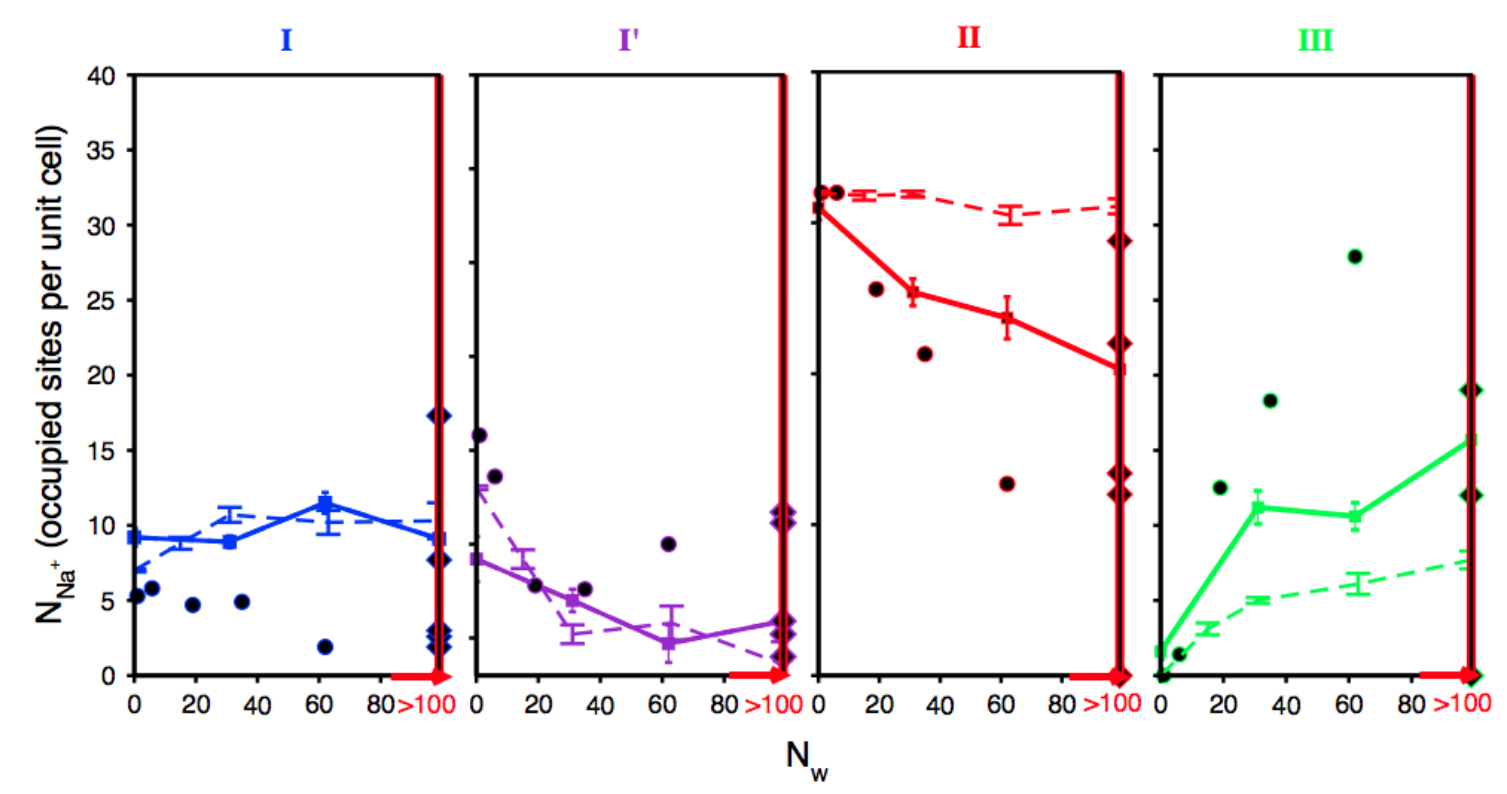

Figure 12: Number of cations per unit cell in the various sites (I, I', II and III) as a function of the number of water molecules per unit cell, $N_{w}$. For each site, we compare the present simulation results with the PIM (solid lines) to the experimental results of Ref. 101 (circles), as well as the simulation results of the same reference using a non-polarizable force field and a rigid framework (dashed lines). For the most hydrated states, the experimental water content is not known accurately and we report all the results on the right axis under the label $\left(N_{w}>100\right)$ (diamonds). The corresponding experimental data are taken from Refs. 108-112, while our simulation results with the PIM are summarized in Table 7 
prediction of the occupancy of sites II and III, compared to the previously available non-polarizable force field (which in addition required to treat the framework as rigid). Indeed, it correctly captures the experimental decrease in occupancy of sites II upon hydration (which the previous model failed to reproduce) as well as the larger increase in the number of occupied sites III with increasing water content.

Table 7: Number of sites per unit cell occupied by sodium cations in $\mathrm{Na}_{58} \mathrm{Y}$ faujasite as a function of the number of water molecules per unit cell, $N_{w}$. The total number of sites I, I', II and III per unit cell are 16, 32, 32 and 48, respectively.

\begin{tabular}{ccccc}
\hline \hline$N_{w}$ & I & I' & II & III \\
\hline 0 & $9.2(0.6)$ & $14.2(1.2)$ & $31(0.8)$ & $1.6(0.5)$ \\
31 & $8.9(0.4)$ & $12(0.6)$ & $25.4(0.9)$ & $10.6(0.9)$ \\
62 & $11.5(0.7)$ & $9.7(1.1)$ & $23.7(1.4)$ & $11.2(1.1)$ \\
123 & $10.2(0.8)$ & $9.4(1.1)$ & $19.7(1.5)$ & $16.5(1.5)$ \\
163 & $7.9(0.4)$ & $12.4(1.2)$ & $20.9(1.8)$ & $14.9(2.1)$ \\
\hline
\end{tabular}

\section{Conclusion and perspectives}

We have extended the PIM polarizable force field to hydrated montmorillonite clays. Following our previous work, we parametrized this model on DFT calculations, thereby avoiding the resort to experimental data in this process - unlike other force fields. Experimental data is then only used for validation purposes. Specifically, the distribution of ions and water in the interlayer predicted by this force field is in very good agreement with experimental XRD patterns, even better than the state-of-the-art non-polarizable model CLAYFF. This improvement can be traced back to the stronger repulsion of water from the surfaces in the PIM case, as well as to the better description of the distortion of the mineral layers due to the presence of the cations (as for dry montmorillonite). Similarly, we obtain a good agreement between the water diffusion coefficients predicted with the PIM and the experimental estimates from QENS. Here again, the predictions of CLAYFF are slightly different, in terms of water diffusion coefficients and diffusion pathways for cations. Such an agreement with experimental results is remarkable given that no experimental data was used in 
the parametrization process. Finally, we further illustrated the power of the newly developed PIM by showing its transferability to other aluminosilicates, on the case of faujasite zeolites, which display a three-dimensional framework (in contrast two the two-dimensional structure of clays). In this case too, the PIM suggest an improvement over existing non-polarizable force fields, as demonstrated here for the prediction of the distribution of cations among the possible sites as a function of water content.

Several extensions of this work can now be considered. In the near future we plan to investigate clays with tetrahedral substitutions. In particular, we already have additional experimental data for saponite clays, such as neutron diffraction on natural and deuterated samples which would provide additional constraints for the validation of the atomic distribution of $\mathrm{H}$ atoms. ${ }^{23}$ The PIM force field will also be extended to fluorohectorites. The interest for these clays is twofold. On the one hand, these are synthetic clays with clearly identified hydration states (with limited or no interstratification) and we already have experimental data on their structure and dynamics which could be directly compared to simulations. On the other hand, we expect that the PIM model will successfully help us to elucidate the role of fluorine on the hydrophobicity of clays, such as lower water uptakes compared to hydroxylated hectorites for a same layer-to-layer distance. Finally, polarizability could play a more important role in systems containing a single interface, or in unsaturated clays. It has indeed been shown that using polarizable force fields led to rather different

distributions of the species at the air/water interface, in better agreement with experiments. ${ }^{37,113}$ Accounting for polarizability will also be essential to correcly predict the sorption of polarizable species in porous media such as clays or zeolites and we plan to extend this approach to other types of ions and aluminosilicates.

\section{Supporting Information Available}

The supporting information contain:

- The parameters of the PIM force field obtained on dry montmorillonites. 
- The characteristics of the simulated system for the comparison with XRD data.

- The structural results for hydrated Cs and Ca-montmorillonites.

This material is available free of charge via the Internet at http://pubs acs.org/.

\section{Acknowledgement}

S.T. acknowledges financial support from Labex MiChem, W.L. acknowledges the financial support from Region Ile-de-France via the DIM OXYMORE. V.M and E.F acknowledge financial support from NEEDS-MIPOR via project TRANSREAC. We also thank the Direction des Systèmes d'Information of Jussieu for access to computational resources. We are grateful for the computing resources on OCCIGEN (CINES, French National HPC) obtained through the projects x2015097321. 


\section{References}

(1) Sato, T.; Watanabe, T.; Otsuka, R. Effects of layer charge, charge location, and energy change on expansion properties of dioctahedral smectites. Clays Clay Miner. 1992, 40, 103113.

(2) Sato, T.; Murakami, T.; Watanabe, T. Change in layer change of smectites and smectite layers in illite/smectite during diagenetic alteration. Clays Clay Miner. 1996, 44, 460-469.

(3) Chang, F.-R. C.; Skipper, N. T.; Sposito, G. Computer simulation of interlayer molecular structure in sodium montmorillonite hydrates. Langmuir 1995, 11, 2734-2741.

(4) Fuchs, A. H.; Cheetham, A. K. Adsorption of guest molecules in zeolitic materials: Computational aspects. J. Phys. Chem. B 2001, 105, 7375-7383.

(5) Hensen, E. J. M.; Smit, B. Why clays swell. J. Phys. Chem. B 2002, 106, 12664-12667.

(6) Marry, V.; Turq, P.; Cartailler, T.; Levesque, D. Microscopic simulation of structure and dynamics of water and counterions in a monohydrated montmorillonite. J. Chem. Phys. 2002, 117, 3454-3463.

(7) Smit, B.; Krishna, R. Molecular simulations in zeolitic process design. Chem. Eng. Sci. 2003, 58, 557-568.

(8) Tambach, T. J.; Hensen, E. J. M.; Smit, B. Molecular simulations of swelling clay minerals. J. Phys. Chem. B 2004, 108, 7586-7596.

(9) Smith, D. E.; Wang, Y.; Chaturvedi, A.; Whitley, H. D. Molecular simulations of the pressure, temperature, and chemical potential dependencies of clay swelling. J. Phys. Chem. B 2006, 110, 20046-20054.

(10) Wang, J.; Kalinichev, A. G.; Kirkpatrick, R. J. Effects of substrate structure and composition on the structure, dynamics, and energetics of water at mineral surfaces: A molecular dynamics modeling study. Geochim. Cosmochim. Ac. 2006, 70, 562-582. 
(11) Kosakowski, G.; Churakov, S. V.; Thoenen, T. Diffusion of Na and Cs in montmorillonite. Clays Clay Miner. 2008, 56, 190-206.

(12) Marry, V.; Rotenberg, B.; Turq, P. Structure and dynamics of water at a clay surface from molecular dynamics simulation. Phys. Chem. Chem. Phys. 2008, 10, 4802-4813.

(13) Suter, J. L.; Anderson, R. L.; Greenwell, H. C.; Coveney, P. V. Recent advances in largescale atomistic and coarse-grained molecular dynamics simulation of clay minerals. $J$. Mater. Chem. 2009, 19, 2482-2493.

(14) Bourg, I. C.; Sposito, G. Molecular dynamics simulations of the electrical double layer on smectite surfaces contacting concentrated mixed electrolyte $(\mathrm{NaCl}-\mathrm{CaCl} 2)$ solutions. $J$. Colloid Interface Sci. 2011, 360, 701-715.

(15) Rotenberg, B.; Patel, A. J.; Chandler, D. Molecular explanation for why talc surfaces can be both hydrophilic and hydrophobic. J. Am. Chem. Soc. 2011, 133, 20521-20527.

(16) Botan, A.; Marry, V.; Rotenberg, B.; Turq, P.; Noetinger, B. How electrostatics influences hydrodynamic boundary conditions: Poiseuille and electro-osmostic flows in clay nanopores. J. Phys. Chem. C 2013, 117, 978-985.

(17) Teich-McGoldrick, S. L.; Greathouse, J. A.; Jove-Colon, C. F.; Cygan, R. T. Swelling properties of montmorillonite and beidellite clay minerals from molecular simulation: Comparison of temperature, interlayer cation, and charge location effects. J. Phys. Chem. C 2015, 119, 20880-20891.

(18) Szczerba, M.; Kuligiewicz, A.; Derkowski, A.; Gionis, V.; Chryssikos, G. D.; Kalinichev, A. G. Structure and dynamics of water-smectite interfaces: Hydrogen bonding and the origin of the sharp O-DW/O-HW infrared band from molecular simulations. Clays Clay Miner. 2016, 64, 452-471. 
(19) Greathouse, J. A.; Cygan, R. T.; Fredrich, J. T.; Jerauld, G. R. Molecular dynamics simulation of diffusion and electrical conductivity in montmorillonite interlayers. J. Phys. Chem. C 2016, 120, 1640-1649.

(20) Mellot-Draznieks, C.; Buttefey, S.; Boutin, A.; Fuchs, A. H. Placement of cations in NaX faujasite-type zeolite using (N,V,T) monte carlo simulations. Chem. Commun. 2001, 22002201.

(21) Coudert, F.-X.; Cailliez, F.; Vuilleumier, R.; Fuchs, A. H.; Boutin, A. Water nanodroplets confined in zeolite pores. Farad. Disc. 2009, 141, 377-398.

(22) Marry, V.; Dubois, E.; Malikova, N.; Durand-Vidal, S.; Longeville, S.; Breu, J. Water dynamics in hectorite clays: Influence of temperature studied by coupling neutron spin echo and molecular dynamics. Environ. Sci. Technol. 2011, 45, 2850-2855.

(23) Ferrage, E.; Sakharov, B. A.; Michot, L. J.; Delville, A.; Bauer, A.; Lanson, B.; Grangeon, S.; Frapper, G.; Jiménez-Ruiz, M.; Cuello, G. J. Hydration properties and interlayer organization of water and ions in synthetic Na-smectite with tetrahedral layer charge. Part 2. Toward a precise coupling between molecular simulations and diffraction data. J. Phys. Chem. C 2011, 115, 1867-1881.

(24) Marry, V.; Dubois, E.; Malikova, N.; Breu, J.; Haussler, W. Anisotropy of water dynamics in clays: Insights from molecular simulations for experimental QENS analysis. J. Phys. Chem. C 2013, 117, 15106-15115.

(25) Skipper, N. T.; Retson, K.; McConnell, J. D. C. Computer calculation of water-clay interactions using atomic pair potentials. Clay Miner. 1989, 24, 411-25.

(26) Delville, A. Structure and properties of confined liquids: A molecular model of the claywater interface. J. Phys. Chem. 1993, 97, 9703-9712. 
(27) Skipper, N. T.; Chang, F.-R. C.; Sposito, G. Monte carlo simulation of interlayer molecular structure in swelling clay minerals. I: Methodology. Clays Clay Miner. 1995, 43, 285-293.

(28) Teppen, B. J.; Rasmussen, K.; Bertsch, P. M.; Miller, D. M.; Schäfer, L. Molecular dynamics modeling of clay minerals. 1. Gibbsite, kaolinite, pyrophyllite, and beidellite. J. Phys. Chem. B 1997, 101, 1579-1587.

(29) Jaramillo, E.; Auerbach, S. M. New force field for Na cations in faujasite-type zeolites. J. Phys. Chem. B 1999, 103, 9589-9594.

(30) Buttefey, S.; Boutin, A.; Mellot-Draznieks, C.; Fuchs, A. H. A simple model for predicting the $\mathrm{Na}^{+}$distribution in anhydrous $\mathrm{NaY}$ and $\mathrm{NaX}$ zeolites. J. Phys. Chem. B 2001, 105, 9569-9575.

(31) Sainz-Diaz, C. I.; Hernández-Laguna, A.; Dove, M. T. Modeling of dioctahedral 2:1 phyllosilicates by means of transferable empirical potentials. Phys. Chem. Miner. 2001, 28, 130141.

(32) Cygan, R. T.; Liang, J.-J.; Kalinichev, A. G. Molecular models of hydroxide, oxyhydroxide, and clay phases and the development of a general force field. J. Phys. Chem. B 2004, 108, $1255-1266$.

(33) Di Lella, A.; Desbiens, N.; Boutin, A.; Demachy, I.; Ungerer, P.; Bellat, J.-P.; Fuchs, A. H. Molecular simulation studies of water physisorption in zeolites. Phys. Chem. Chem. Phys. 2006, 8, 5396-5406.

(34) Pitman, M. C.; van Duin, A. C. T. Dynamics of confined reactive water in smectite clayzeolite composites. J. Am. Chem. Soc. 2012, 134, 3042-3053.

(35) Molina, J. J.; Lectez, S.; Tazi, S.; Salanne, M.; Dufrêche, J.-F.; Roques, J.; Simoni, E.; Madden, P. A.; Turq, P. Ions in solutions: Determining their polarizabilities from first-principles. J. Chem. Phys. 2011, 134, 014511. 
(36) Tazi, S.; Molina, J. J.; Rotenberg, B.; Turq, P.; Vuilleumier, R.; Salanne, M. A transferable ab initio based force field for aqueous ions. J. Chem. Phys. 2012, 136, 114507.

(37) Jungwirth, P.; Tobias, D. J. Specific ion effects at the air/water interface. Chem. Rev. 2006, $106,1259-1281$.

(38) Lopes, P. E. M.; Roux, B.; MacKerell, A. D. Molecular modeling and dynamics studies with explicit inclusion of electronic polarizability: Theory and applications. Theor. Chem. Acc. 2009, 124, 11-28.

(39) Cieplak, P.; Dupradeau, F.-Y.; Duan, Y.; Wang, J. Polarization effects in molecular mechanical force fields. J. Phys.: Condens. Matter 2009, 21, 333102.

(40) Baker, C. M. Polarizable force fields for molecular dynamics simulations of biomolecules. WIREs Comput. Mol. Sci. 2015, 5, 241-254.

(41) Lamoureux, G.; Roux, B. Modeling induced polarization with classical Drude oscillators: Theory and molecular dynamics simulation algorithm. J. Chem. Phys. 2003, 119, 30253039.

(42) Ponder, J. W.; Wu, C.; Ren, P.; Pande, V. S.; Chodera, J. D.; Schnieders, M. J.; Haque, I.; Mobley, D. L.; Lambrecht, D. S.; DiStasio, R. A.; Head-Gordon, M.; Clark, G. N. I.; Johnson, M. E.; Head-Gordon, T. Current Status of the AMOEBA Polarizable Force Field. J. Phys. Chem. B 2010, 114, 2549-2564.

(43) Tesson, S.; Salanne, M.; Rotenberg, B.; Tazi, S.; Marry, V. Classical polarizable force field for clays: Pyrophyllite and talc. J. Phys. Chem. C 2016, 120, 3749-3758.

(44) Tesson, S.; Louisfrema, W.; Salanne, M.; Boutin, A.; Rotenberg, B.; Marry, V. Classical polarizable force field to study dry charged clays and zeolites. J. Phys. Chem. C 2017, 121, 9833-9846. 
(45) Fumi, F. G.; Tosi, M. P. Ionic sizes and born repulsive parameters in the NaCl-type alkali halides-I: The huggins-mayer and pauling forms. J. Phys. Chem. Solids 1964, 25, 31-43.

(46) Tosi, M. P.; Fumi, F. G. Ionic sizes and born repulsive parameters in the NaCl-type alkali halides-II: The generalized huggins-mayer form. J. Phys. Chem. Solids 1964, 25, 45-52.

(47) Wang, B.; Truhlar, D. G. Including charge penetration effects in molecular modeling. J. Chem. Theory Comput. 2010, 6, 3330-3342.

(48) Tang, K. T.; Toennies, J. P. An improved simple model for the van der waals potential based on universal damping functions for the dispersion coefficients. J. Chem. Phys. 1984, 80, $3726-3741$.

(49) Jahn, S.; Madden, P. A. Modeling earth materials from crustal to lower mantle conditions: A transferable set of interaction potentials for the CMAS system. Phys. Earth Planet. In. 2007, 162, 129-139.

(50) Dang, L. X.; Chang, T. M. Molecular dynamics study of water clusters, liquid, and liquidvapor interface of water with many-body potentials. J. Chem. Phys. 1997, 106, 8149-8159.

(51) CP2K developers group, See http://cp2k.berlios.de. http://cp2k . berlios.de, (accessed October 15, 2015).

(52) Martyna, G. J.; Klein, M. L.; Tuckerman, M. Nosé-Hoover chains: The canonical ensemble via continuous dynamics. J. Chem. Phys. 1992, 97, 2635-2643.

(53) Aguado, A.; Bernasconi, L.; Jahn, S.; Madden, P. A. Multipoles and interaction potentials in ionic materials from planewave-DFT calculations. Faraday Discuss. 2003, 124, 171-184.

(54) Laino, T.; Hutter, J. Notes on "Ewald summation of electrostatic multipole interactions up to quadrupolar level" [J. Chem. Phys.119, 7471 (2003)]. J. Chem. Phys. 2008, 129, 074102.

(55) Perdew, J. P.; Burke, K.; Ernzerhof, M. Generalized gradient approximation made simple. Phys. Rev. Lett. 1996, 77, 3865-3868. 
(56) Goedecker, S.; Teter, M.; Hutter, J. Separable dual-space gaussian pseudopotentials. Phys. Rev. B 1996, 54, 1703-1710.

(57) Hartwigsen, C.; Goedecker, S.; Hutter, J. Relativistic separable dual-space gaussian pseudopotentials from H to Rn. Phys. Rev. B 1998, 58, 3641-3662.

(58) Krack, M. Pseudopotentials for $\mathrm{H}$ to $\mathrm{Kr}$ optimized for gradient-corrected exchangecorrelation functionals. Theor. Chem. Acc. 2005, 114, 145-152.

(59) VandeVondele, J.; Hutter, J. Gaussian basis sets for accurate calculations on molecular systems in gas and condensed phases. J. Chem. Phys. 2007, 127, 114105.

(60) Silvestrelli, P. L. Maximally localized wannier functions for simulations with supercells of general symmetry. Phys. Rev. B 1999, 59, 9703.

(61) Marzari, N.; Souza, I.; Vanderbilt, D. An introduction to maximally-localized wannier functions. Psi-K newsletter 2003, 57, 129-168.

(62) James, F.; Roos, M. Minuit - a system for function minimization and analysis of the parameter errors and correlations. Comput. Phys. Commun. 1975, 10, 343-367.

(63) Mooney, R. W.; Keenan, A. G.; Wood, L. A. Adsorption of water vapor by montmorillonite. II. Effect of exchangeable ions and lattice swelling as measured by x-ray diffraction. J. Am. Chem. Soc. 1952, 74, 1371-1374.

(64) Fu, M. H.; Zhang, Z. Z.; Low, P. F. Changes in the properties of a montmorillonite-water system during the adsorption and desorption of water: Hysteresis. Clays Clay Miner. 1990, $38,485-492$.

(65) Bérend, I.; Cases, J. M.; François, M.; Uriot, J. P.; Michot, L.; Masion, A.; Thomas, F. Mechanism of adsorption and desorption of water-vapor by homoionic montmorillonites. 2. The $\mathrm{Li}^{+}, \mathrm{Na}^{+}, \mathrm{K}^{+}, \mathrm{Rb}^{+}$, and $\mathrm{Cs}^{+}$-exchanged forms. Clays Clay Miner. 1995, 43, 324336. 
(66) Cases, J. M.; Bérend, I.; François, M.; Uriot, J. P.; Michot, L. J.; Thomas, F. Mechanism of adsorption and desorption of water vapor by homoionic montmorillonite. 3. $\mathrm{The}^{\mathrm{Mg}}{ }^{2+}$, $\mathrm{Ca}^{2+}, \mathrm{Sr}^{2+}$ and $\mathrm{Ba}^{2+}$-exchanged forms. Clays Clay Miner. 1997, 45, 8-22.

(67) Ferrage, E.; Lanson, B.; Sakharov, B. A.; Drits, V. A. Investigation of smectite hydration properties by modeling experimental x-ray diffraction patterns: Part I. Montmorillonite hydration properties. Am. Miner. 2005, 90, 1358-1374.

(68) Ferrage, E.; Lanson, B.; Malikova, N.; Plançon, A.; Sakharov, B.; Drits, V. A. New insights on the distribution of interlayer water in bi-hydrated smectite from x-ray diffraction profile modeling of 001 reflections. Chem. Mater. 2005, 17, 3499-3512.

(69) Melkior, T.; Gaucher, E. C.; Brouard, C.; Yahiaoui, S.; Thoby, D.; Clinard, C.; Ferrage, E.; Guyonnet, D.; Tournassat, C.; Coelho, D. $\mathrm{Na}^{+}$and HTO diffusion in compacted bentonite: Effect of surface chemistry and related texture. J. Hydrol. 2009, 370, 9-20.

(70) Hånde, R.; Ramothe, V.; Tesson, S.; Dazas, B.; Ferrage, E.; Lanson, B.; Salanne, M.; Rotenberg, B.; Marry, V. Classical polarizable force field to study hydrated hectorite: Optimization on DFT calculations and validation against XRD data. Minerals 2018, 8, 205.

(71) Drits, V. A.; Besson, G.; Muller, F. An improved model for structural transformation of heattreated aluminous dioctahedral 2: 1 layer silicates. Clays Clay Miner. 1995, 43, 718-731.

(72) Abascal, J. L. F.; Vega, C. A general purpose model for the condensed phases of water: TIP4P/2005. J. Chem. Phys. 2005, 123, 234505.

(73) Vega, C.; Abascal, J. L. F.; Nezbeda, I. Vapor-liquid equilibria from the triple point up to the critical point for the new generation of TIP4P-like models: TIP4P/Ew, TIP4P/2005, and TIP4P/ice. J. Chem. Phys. 2006, 125, 034503.

(74) Abascal, J. L. F.; Vega, C. Widom line and the liquid-liquid critical point for the TIP4P/2005 water model. J. Chem. Phys. 2010, 133, 234502. 
(75) Tazi, S.; Boţan, A.; Salanne, M.; Marry, V.; Turq, P.; Rotenberg, B. Diffusion coefficient and shear viscosity of rigid water models. J. Phys.: Condens. Matter 2012, 24, 284117.

(76) Kroutil, O.; Chval, Z.; Skelton, A. A.; Predota, M. Computer simulations of quartz (101)water interface over a range of pH values. J. Phys. Chem. C 2015, 119, 9274-9286.

(77) Ferrage, E. Investigation of the interlayer organization of water and ions in smectite from the combined use of diffraction experiments and molecular simulations. A review of methodology, applications, and perspectives. Clays Clay Miner. 2016, 64, 348-373.

(78) Malikova, N.; Cadène, A.; Marry, V.; Dubois, E.; Turq, P. Diffusion of water in clays on the microscopic scale: modeling and experiment. J. Phys. Chem. B 2006, 110, 3206-3214.

(79) Malikova, N.; Dubois, E.; Marry, V.; Rotenberg, B.; Turq, P. Dynamics in clays-combining neutron scattering and microscopic simulation. Z. Phys. Chem. 2010, 224, 153-181.

(80) Frenkel, D.; Smit, B. Understanding molecular simulation: from algorithms to applications, academic press ed.; Computational Science, 2002; Vol. 1.

(81) Flyvbjerg, H.; Petersen, H. G. Error estimates on averages of correlated data. J. Chem. Phys. 1989, 91, 461-466.

(82) Zheng, Y.; Zaoui, A. How water and counterions diffuse into the hydrated montmorillonite. Solid State Ionics 2011, 203, 80-85.

(83) Bourg, I. C.; Sposito, G. Connecting the molecular scale to the continuum scale for diffusion processes in smectite-rich porous media. Environ. Sci. Technol. 2010, 44, 2085-2091.

(84) Holmboe, M.; Bourg, I. C. Molecular dynamics simulations of water and sodium diffusion in smectite interlayer nanopores as a function of pore size and temperature. J. Phys. Chem. C 2014, 118, 1001-1013. 
(85) González Sánchez, F.; Jurányi, F.; Gimmi, T.; Van Loon, L.; Unruh, T.; Diamond, L. W. Translational diffusion of water and its dependence on temperature in charged and uncharged clays: A neutron scattering study. J. Chem. Phys. 2008, 129, 174706.

(86) Zhang, L.; Lu, X.; Liu, X.; Zhou, J.; Zhou, H. Hydration and mobility of interlayer ions of (Na-X, Ca-Y)-montmorillonite: a molecular dynamics study. J. Phys. Chem. C 2014, 118, 29811-29821.

(87) Gates, W. P.; Bordallo, H. N.; Aldridge, L. P.; Seydel, T.; Jacobsen, H.; Marry, V.; Churchman, G. J. Neutron time-of-flight quantification of water desorption isotherms of montmorillonite. J. Phys. Chem. C 2012, 116, 5558-5570.

(88) Tuck, J. J.; Hall, P. L.; Hayes, M. H. B.; Ross, D. K.; Hayter, J. B. Quasi-elastic neutronscattering studies of intercalated molecules in charge-deficient layer silicates. Part 2. Highresolution measurements of the diffusion of water in montmorillonite and vermiculite. $J$. Chem. Soc. Faraday Trans. 1 1985, 81, 833-846.

(89) Marry, V.; Turq, P. Microscopic simulations of interlayer structure and dynamics in bihydrated heteroionic montmorillonites. J. Phys. Chem. B 2003, 107, 1832-1839.

(90) Hall, P. L.; Tuck, J. J.; Hayes, M. H. B.; Ross, D. K. Neutron inelastic scattering 1977; 1978.

(91) Matsuoka, O.; Clementi, E.; Yoshimine, M. CI study of the water dimer potential surface. J. Chem. Phys. 1976, 64, 1351-1361.

(92) Berendsen, H. J. C.; Grigera, J. R.; Straatsma, T. P. The missing term in effective pair potentials. J. Phys. Chem. 1987, 91, 6269-6271.

(93) Teleman, O.; Jönsson, B.; Engström, S. A molecular dynamics simulation of a water model with intramolecular degrees of freedom. Mol. Phys. 1987, 60, 193-203. 
(94) Smith, D. E. Molecular computer simulations of the swelling properties and interlayer structure of cesium montmorillonite. Langmuir 1998, 14, 5959-5967.

(95) Sutton, R.; Sposito, G. Molecular simulation of interlayer structure and dynamics in $12.4 \AA$ Cs-smectite hydrates. J. Colloid Interface Sci. 2001, 237, 174-184.

(96) Yeh, I.-C.; Hummer, G. System-size dependence of diffusion coefficients and viscosities from molecular dynamics simulations with periodic boundary conditions. J. Phys. Chem. B 2004, 108, 15873-15879.

(97) Laury, M. L.; Wang, L.-P.; Pande, V. S.; Head-Gordon, T.; Ponder, J. W. Revised parameters for the AMOEBA polarizable atomic multipole water model. J. Phys. Chem. B 2015, 119, 9423-9437.

(98) Simonnin, P.; Noetinger, B.; Nieto-Draghi, C.; Marry, V.; Rotenberg, B. Diffusion under confinement: Hydrodynamic finite-size effects in simulation. J. Chem. Theory Comput. 2017, 13, 2881-2889.

(99) Database of zeolite structures. http://www.iza-structure.org/databases/, (accessed November 19, 2016).

(100) Jeffroy, M.; Nieto-Draghi, C.; Boutin, A. Molecular simulation of zeolite flexibility. Mol. Simul. 2014, 40, 6-15.

(101) Louisfrema, W.; Rotenberg, B.; Porcher, F.; Paillaud, J.-L.; Massiani, P.; Boutin, A. Cation redistribution upon dehydration of $\mathrm{Na}_{58} \mathrm{Y}$-faujasite zeolite: A joint neutron diffraction and molecular simulation study. Mol. Simul. 2015, 41, 1371-1378.

(102) Louisfrema, W.; Paillaud, J.-L.; Porcher, F.; Perrin, E.; Onfroy, T.; Massiani, P.; Boutin, A.; Rotenberg, B. Cation migration and structural deformations upon dehydration of nickelexchanged NaY-zeolite: A combined neutron diffraction and monte carlo study. J. Phys. Chem. C 2016, 120, 18115-18125. 
(103) Jeffroy, M.; Borissenko, E.; Boutin, A.; Di Lella, A.; Porcher, F.; Souhassou, M.; Lecomte, C.; Fuchs, A. H. Evidence of a framework induced cation redistribution upon water adsorption in cobalt exchanged $\mathrm{x}$ faujasite zeolite: A joint experimental and simulation study. Micropor. Mesopor. Mater. 2011, 138, 45-50.

(104) Abrioux, C.; Coasne, B.; Maurin, G.; Henn, F.; Boutin, A.; Di Lella, A.; Nieto-Draghi, C.; Fuchs, A. H. A molecular simulation study of the distribution of cation in zeolites. Adsorption 2008, 14, 743-754.

(105) Mortier, W. J. Compilation of extra frameword sites in zeolites; Butterworth \& Co. Ltd, 1982.

(106) Jeffroy, M.; Nieto-Draghi, C.; Boutin, A. New molecular simulation method to determine both aluminum and cation location in cationic zeolites. Chem. Mater. 2017, 29, 513-523.

(107) Zhu, L.; Seff, K. Reinvestigation of the crystal structure of dehydrated sodium zeolite X. J. Phys. Chem. B 1999, 103, 9512-9518.

(108) Hseu, T. microfilms, University of Washington, 1972.

(109) Costenoble, M. L.; Mortier, W. J.; Uytterhoeven, J. B. Location of cations in synthetic zeolites $\mathrm{X}$ and Y. Part 4. Exchange limiting factors for $\mathrm{Ca}^{2+}$ in zeolite Y. J. Chem. Soc., Faraday Trans. 1 1976, 72, 1877-1883.

(110) Mortier, W. J.; Van den Bossche, E.; Uytterhoeven, J. B. Influence of the temperature and water adsorption on the cation location in NaY-zeolites. Zeolites 1984, 4, 41-44.

(111) Rubio, J. A.; Soria, J.; Cano, F. H. Influence of the dehydration pretreatment on the cation location in NaY-zeolite. J. Colloid Interface Sci. 1980, 73, 312-323.

(112) Kirschhock, C. E. A.; Hunger, B.; Martens, J.; Jacobs, P. A. Localization of residual water in alkali-metal cation-exchanged X and Y type zeolites. J. Phys. Chem. B 2000, 104, 439-448. 
(113) Ghosal, S.; Hemminger, J. C.; Bluhm, H.; Mun, B. S.; Hebenstreit, E. L. D.; Ketteler, G.; Ogletree, D. F.; Requejo, F. G.; Salmeron, M. Electron spectroscopy of aqueous solution interfaces reveals surface enhancement of halides. Science 2005, 307, 563-566. 


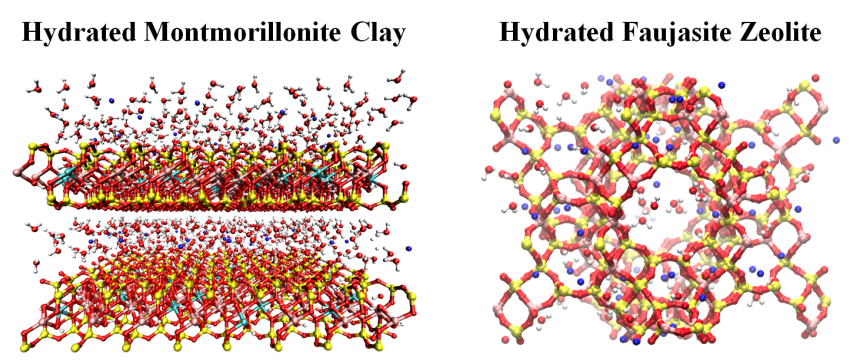

$\bigcirc$ Aluminum $\bigcirc$ Magnesium $\bigcirc$ Hydrogen $\bigcirc$ Oxygen $\bigcirc$ Silicium $\bigcirc$ Sodium 


\section{Supporting Information for Classical Polarizable}

Force Field to Study Hydrated Charged Clays

\section{and Zeolites}

Stéphane Tesson, ${ }^{\dagger}$ Wilfried Louisfrema, ${ }^{\dagger, \ddagger}$ Mathieu Salanne, ${ }^{\dagger}$ Anne Boutin, ${ }^{\ddagger}$ Eric Ferrage, ${ }^{\llbracket}$ Benjamin Rotenberg, ${ }^{\dagger}$ and Virginie Marry*,†

†Sorbonne Université, CNRS, Physicochimie des électrolytes et nanosystèmes interfaciaux, UMR PHENIX, F-75005, Paris, France

$\ddagger$

PASTEUR, Département de Chimie Ecole Normale Supérieure, PSL University, Sorbonne Université, CNRS, 75005 Paris, France

ฯ Université de Poitiers, CNRS, UMR 7285 IC2MP, Equipe HydrASA, 5 rue Albert Turpain, Bât. B8, TSA - 51106, 86073 Poitiers cedex 9, France

E-mail: virginie.marry@sorbonne-universite.fr Phone: +33 (0)144272203 

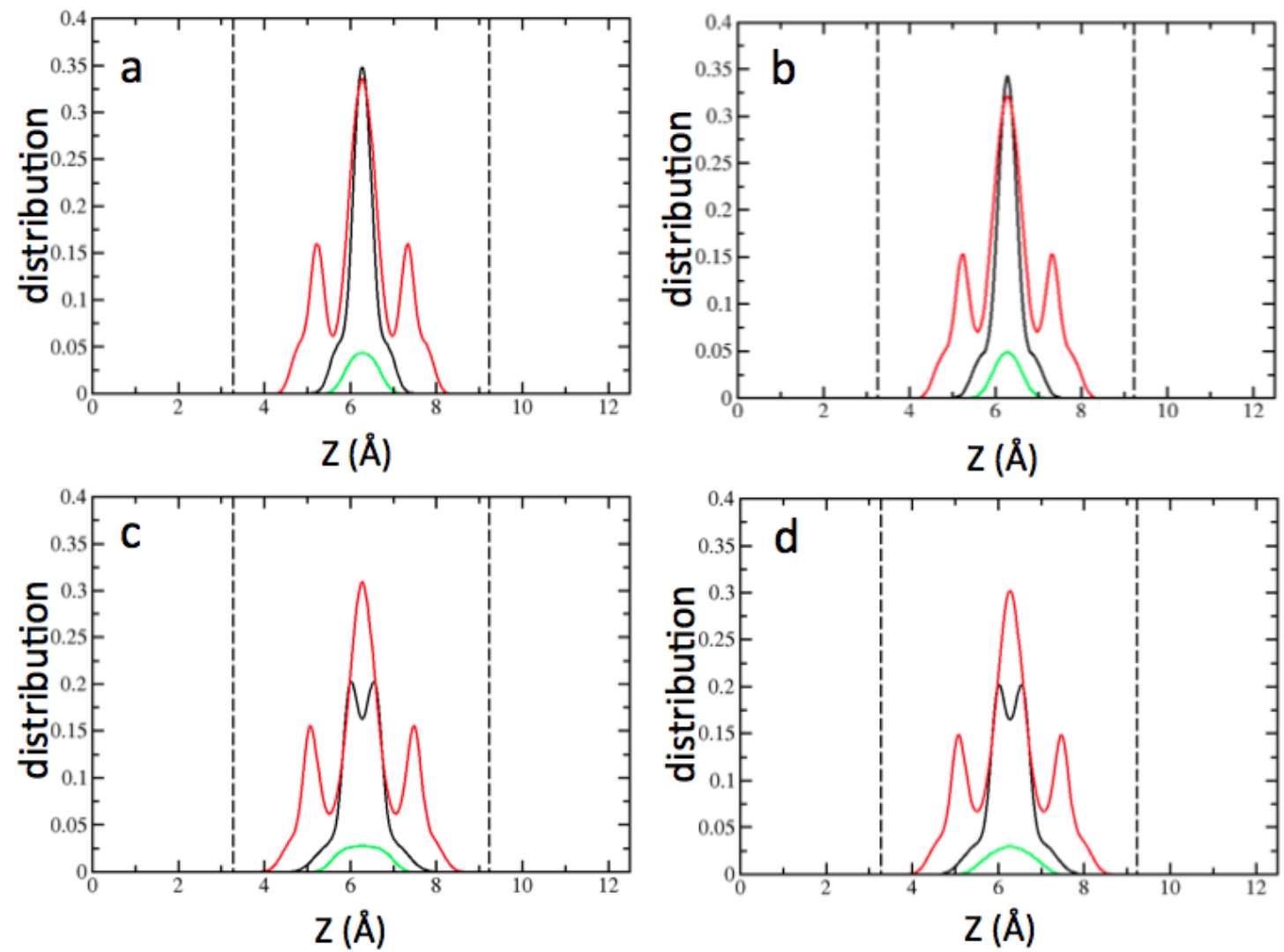

Figure S1: Atomic distributions in the direction perpendicular to the clay layer in monohydrated Cs-montmorillonites. The graph a and b are obtained with the PIM force field. The graph $\mathrm{c}$ and $\mathrm{d}$ are obtained with the CLAYFF force field. The graph a and $\mathrm{c}$ are obtained with a $c v$-Cs-montmorillonite. The graph $\mathrm{b}$ and $\mathrm{d}$ are obtained with a $t v$-Csmontmorillonites. The red, black and green curves are respectively the atomic distribution of the water molecule hydrogen atoms, the water molecule oxygen atoms and the sodium cations. 

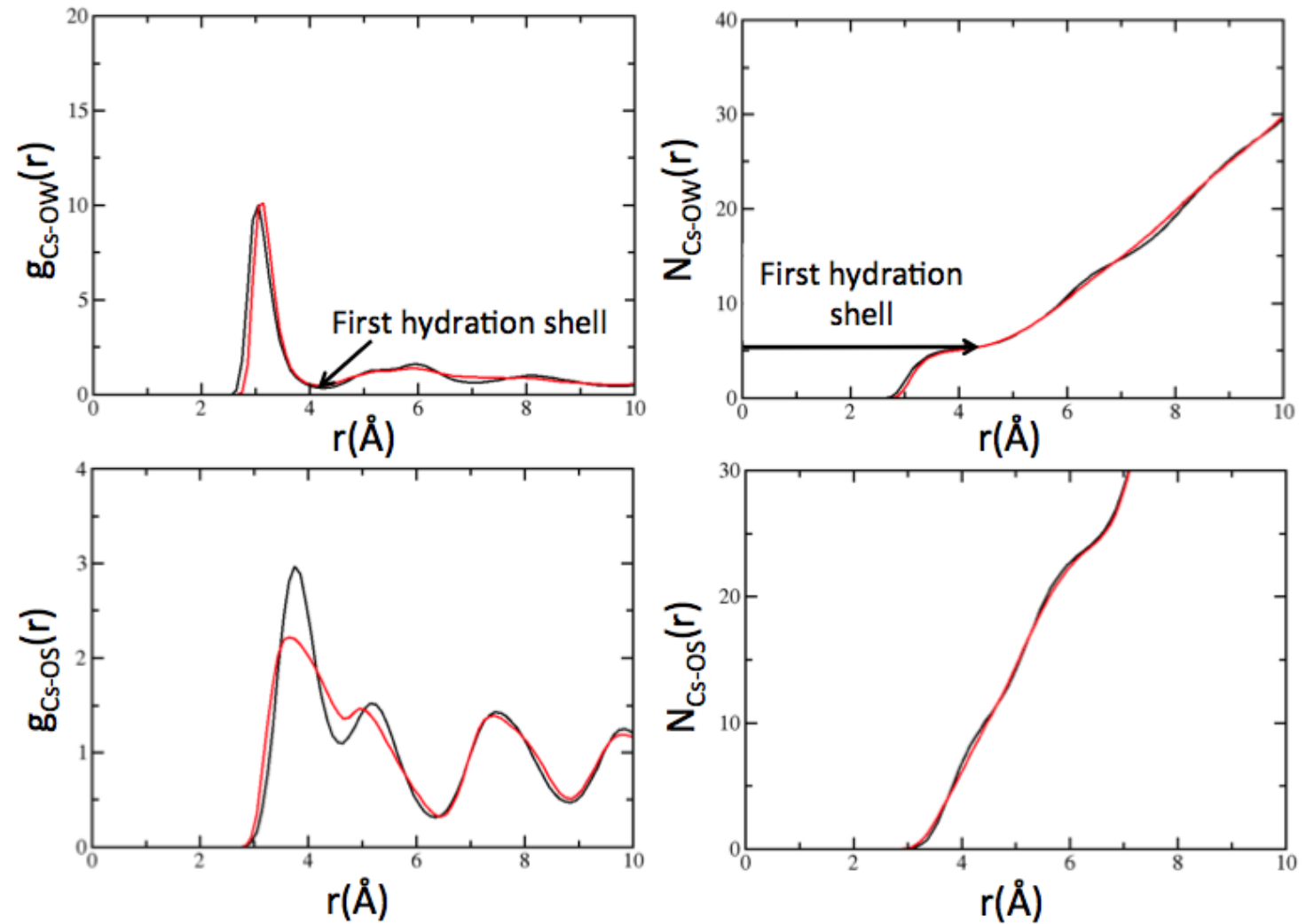

Figure S2: Cation-oxygen radial distribution functions and coordination numbers in monohydrated Cs-montmorillonite. $\mathrm{O}_{W}$ and $\mathrm{O}_{S}$ atoms are water and surface oxygen atoms, respectively. The black and red curves were obtained with PIM and clayFF force fields, respectively. 

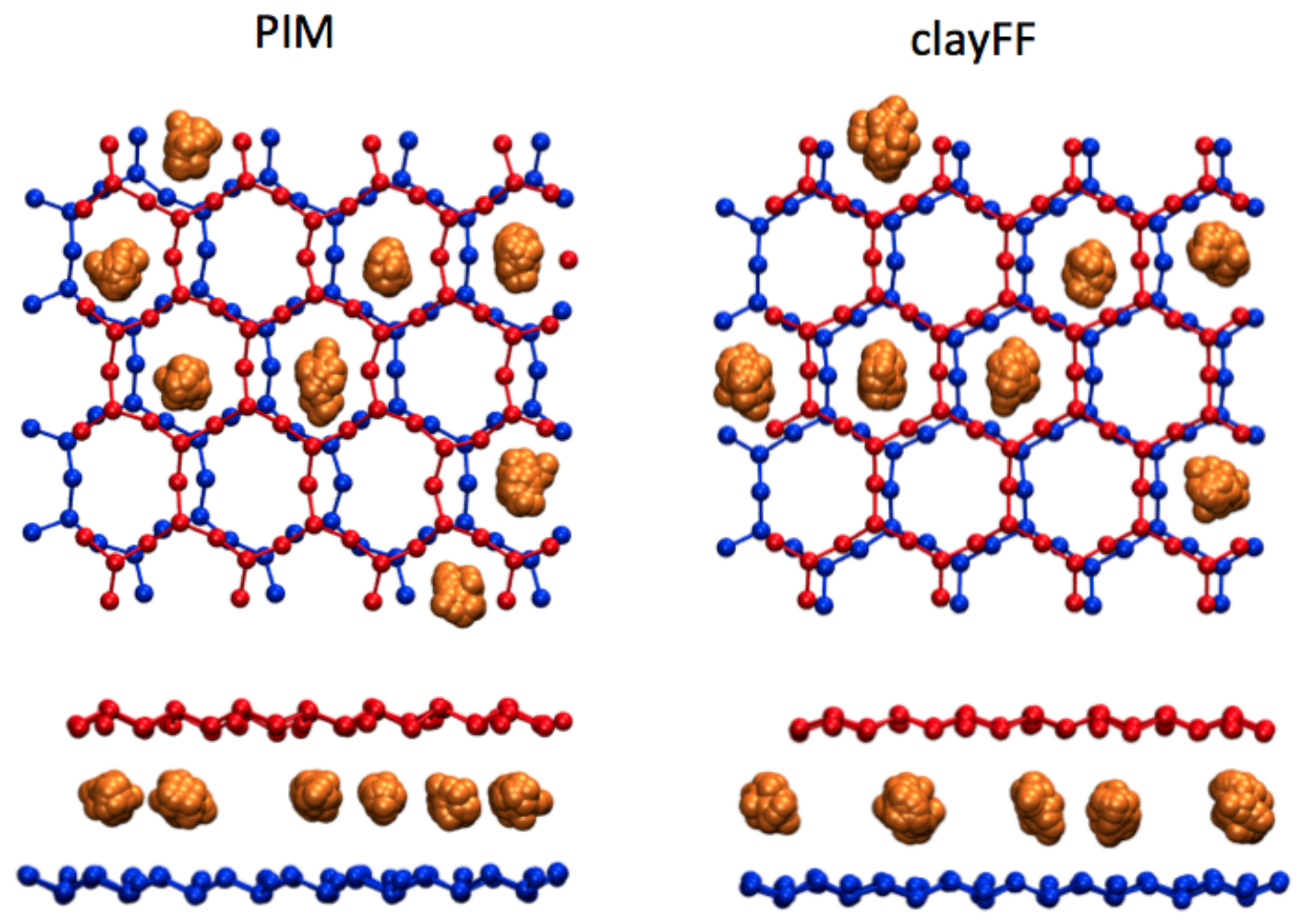

Figure S3: Snapshots obtained in monohydrated Cs-montmorillonite with PIM and clayFF. Only surface silicium and oxygen atoms are represented. Red and blue atoms differentiate the two opposite surfaces. The orange atoms show Cs trajectories over some picoseconds. During this period, clay layer atoms vibrated around their equilibrium position but the layer remained globally fixed. For the sake of clarity only one configuration of the clay layers is represented. 

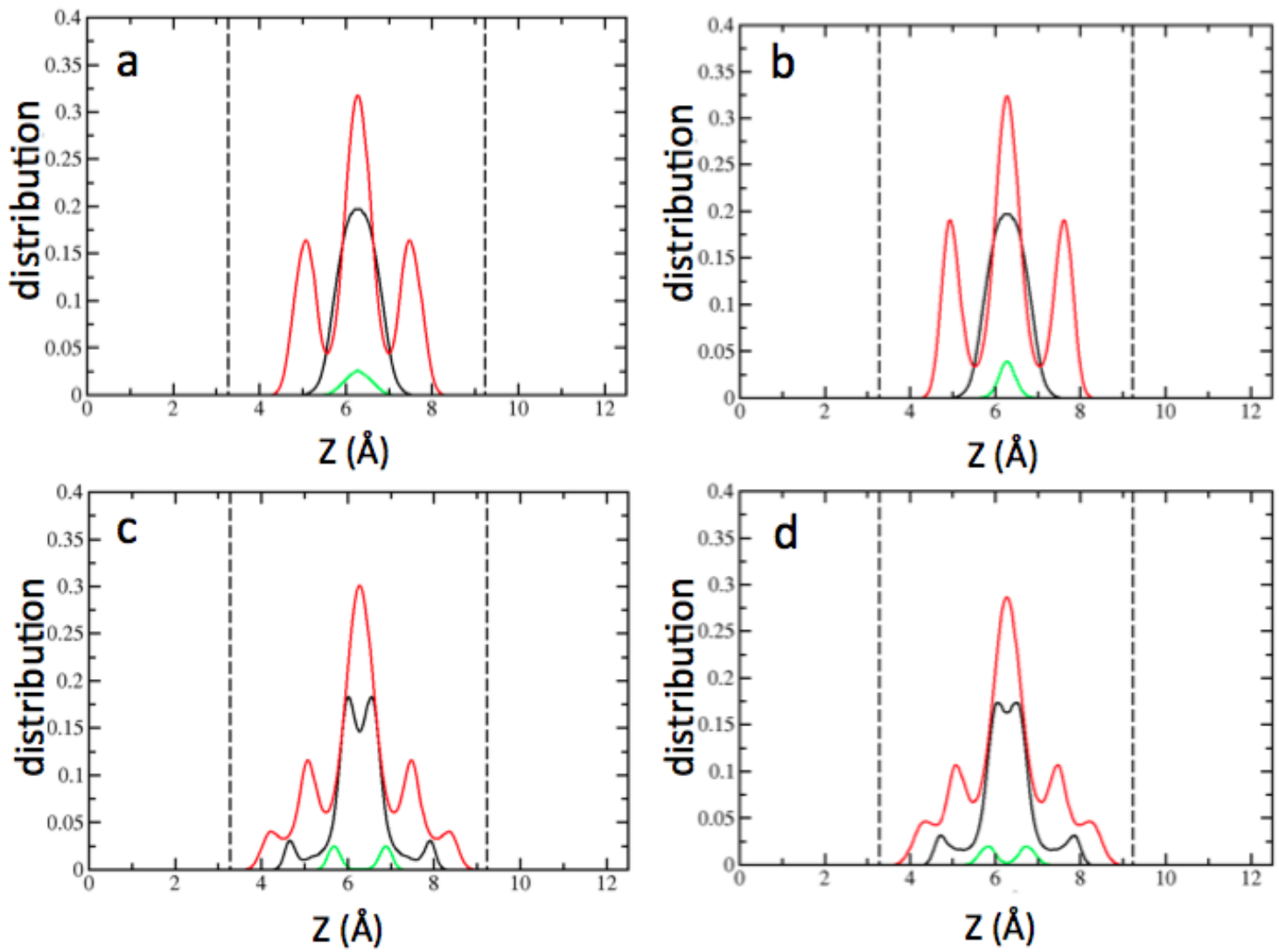

Figure S4: Atomic distributions in the direction perpendicular to the clay layer in monohydrated Ca-montmorillonites. The graph $\mathrm{a}$ and $\mathrm{b}$ are obtained with the PIM force field. The graph $\mathrm{c}$ and $\mathrm{d}$ are obtained with the ClayFF force field. The graph a and $\mathrm{c}$ are obtained with a $c v$-Ca-montmorillonite. The graph $\mathrm{b}$ and $\mathrm{d}$ are obtained with a $t v$-Ca-montmorillonites. The red, black and green curves are respectively the atomic distribution of the water molecule hydrogen atoms, the water molecule oxygen atoms and the calcium cations. 

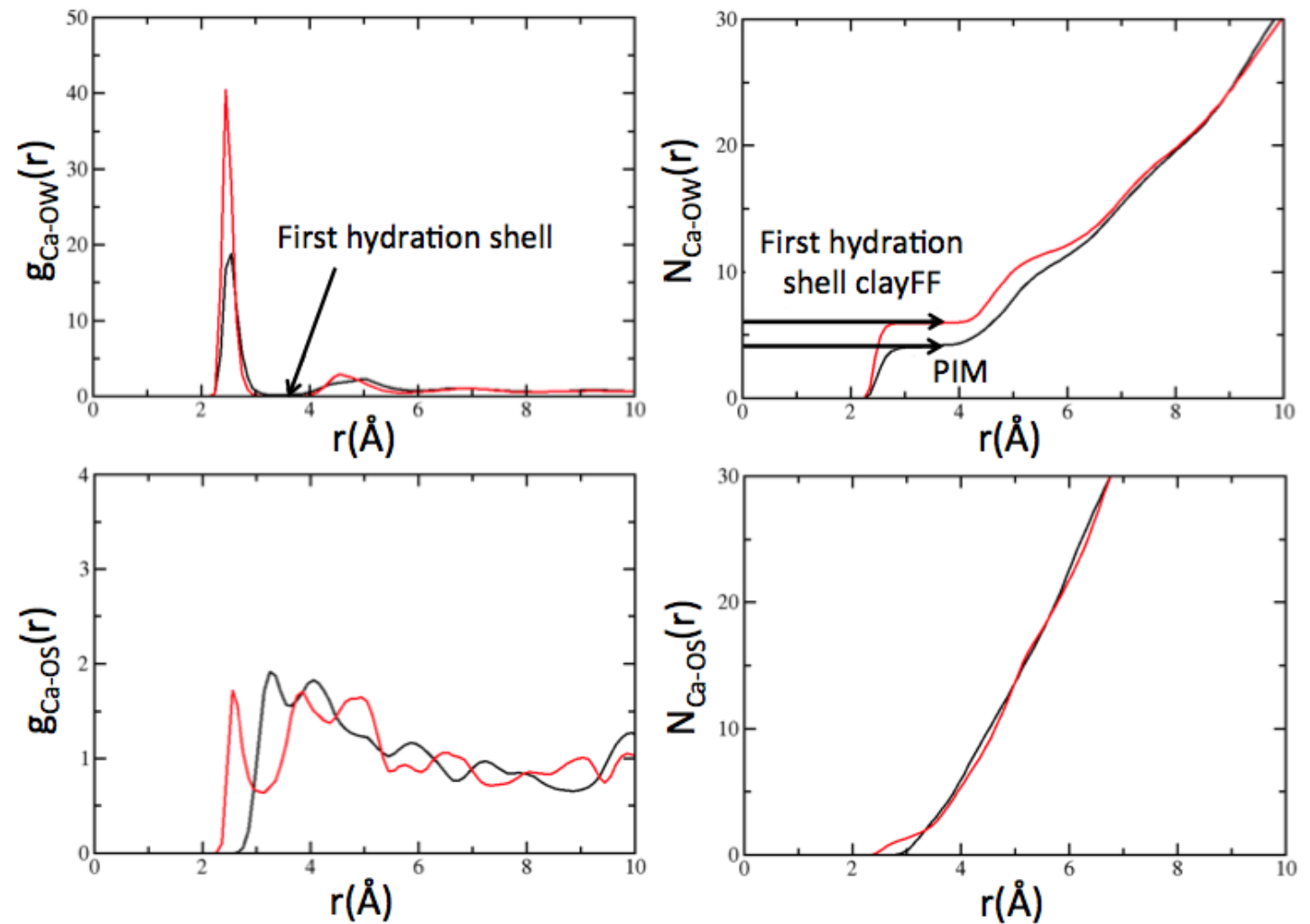

Figure S5: Cation-oxygen radial distribution functions and coordination numbers in monohydrated Ca-montmorillonite. $\mathrm{O}_{W}$ and $\mathrm{O}_{S}$ atoms are water and surface oxygen atoms, respectively. The black and red curves were obtained with PIM and clayFF force fields, respectively. 
PIM
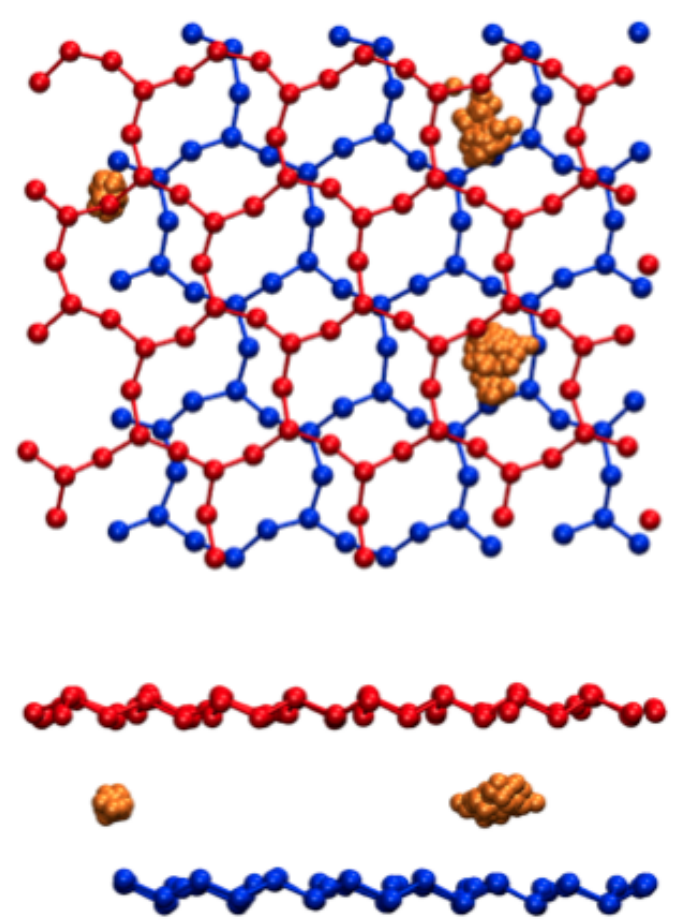

clayFF
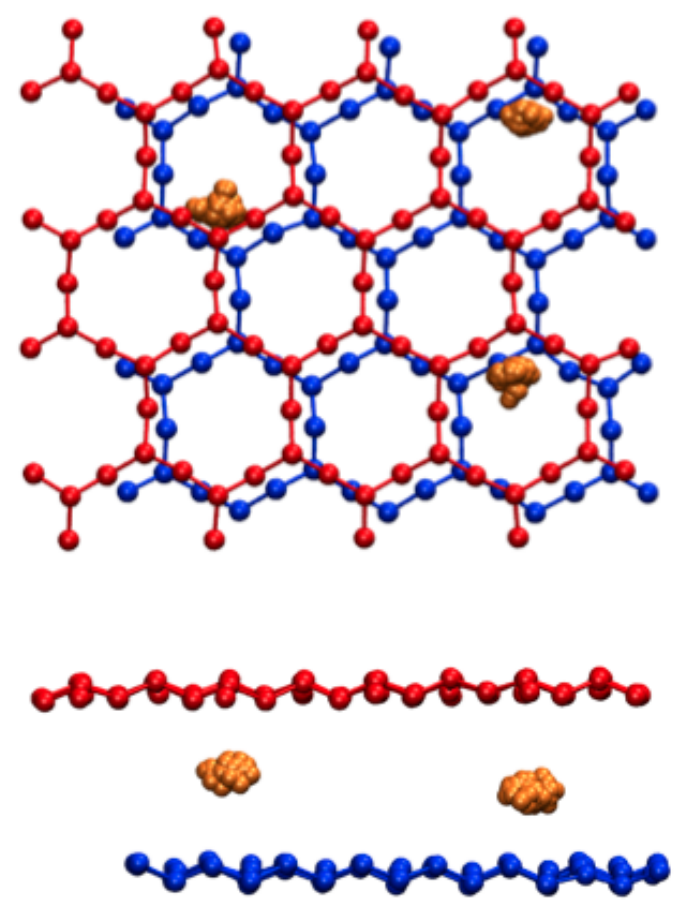

Figure S6: Snapshots obtained in monohydrated Ca-montmorillonite with PIM and clayFF. Only surface silicium and oxygen atoms are represented. Red and blue atoms differentiate the two opposite surfaces. The orange atoms show $\mathrm{Ca}$ trajectories over some picoseconds. During this period, clay layer atoms vibrated around their equilibrium position but the layer remained globally fixed. For the sake of clarity only one configuration of the clay layers is represented. 


\section{References}

(1) Tesson, S.; Salanne, M.; Rotenberg, B.; Tazi, S.; Marry, V. Classical polarizable force field for clays: Pyrophyllite and talc. J. Phys. Chem. C 2016, 120, 3749-3758.

(2) Jahn, S.; Madden, P. A. Modeling earth materials from crustal to lower mantle conditions: A transferable set of interaction potentials for the CMAS system. Phys. Earth Planet. In. 2007, 162, 129-139.

(3) Tesson, S.; Louisfrema, W.; Salanne, M.; Boutin, A.; Rotenberg, B.; Marry, V. Classical polarizable force field to study dry charged clays and zeolites. J. Phys. Chem. C 2017, 121, 9833-9846.

(4) Ferrage, E.; Lanson, B.; Sakharov, B. A.; Drits, V. A. Investigation of smectite hydration properties by modeling experimental x-ray diffraction patterns: Part I. Montmorillonite hydration properties. Am. Miner. 2005, 90, 1358-1374.

(5) Michot, L. J.; Ferrage, E.; Jiménez-Ruiz, M.; Boehm, M.; Delville, A. Anisotropic features of water and ion dynamics in synthetic $\mathrm{Na}$ - and Ca-smectites with tetrahedral layer charge. A combined quasi-elastic neutron-scattering and molecular dynamics simulations study. J. Chem. Phys. C 2012, 116, 16619-16633. 


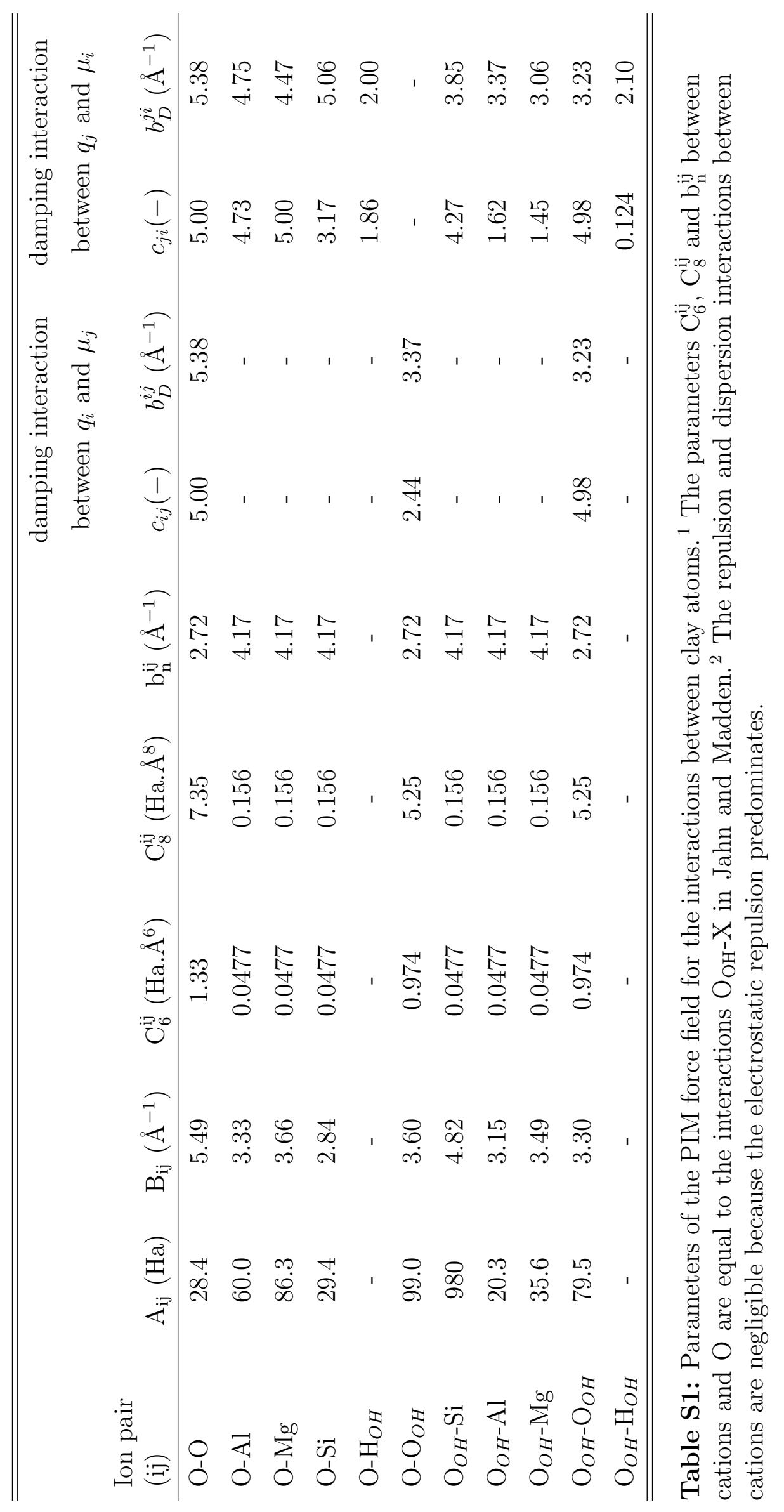




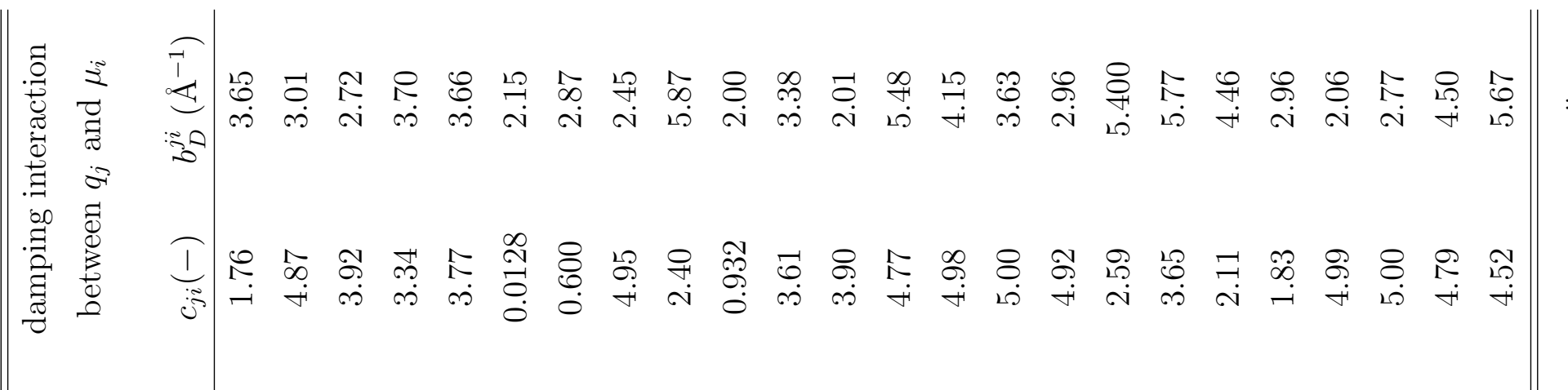

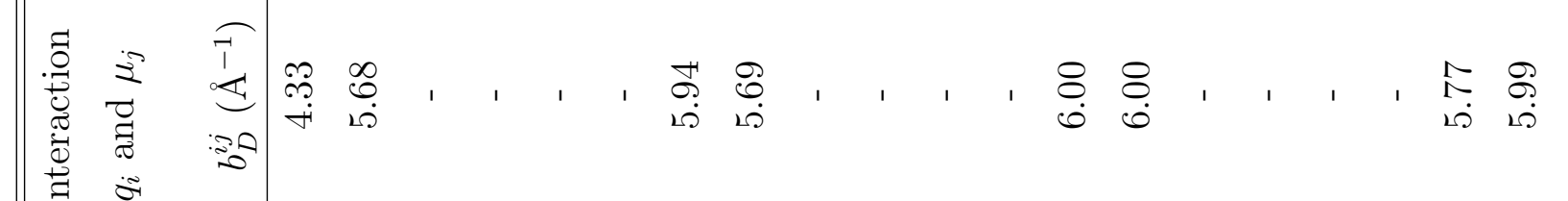

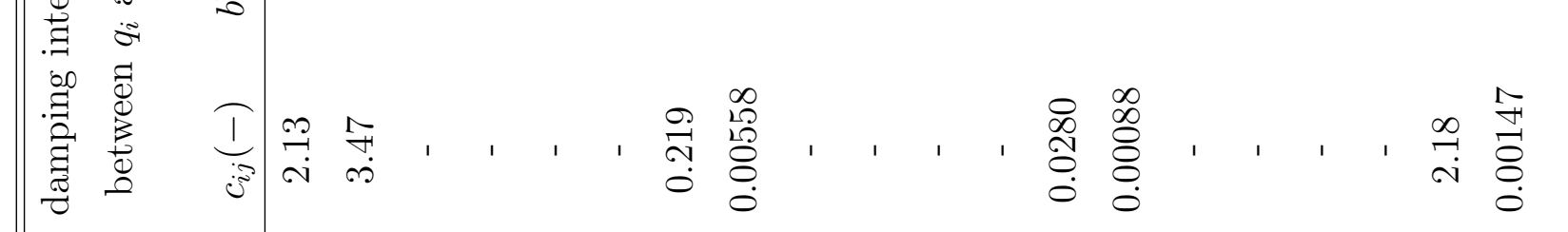

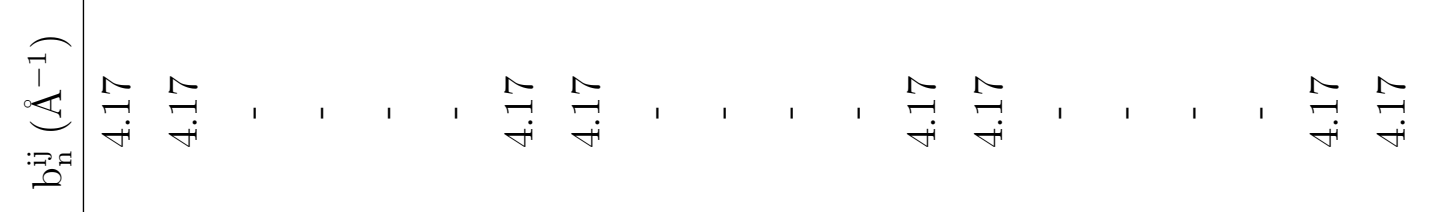

$$
\text { 羿 }
$$

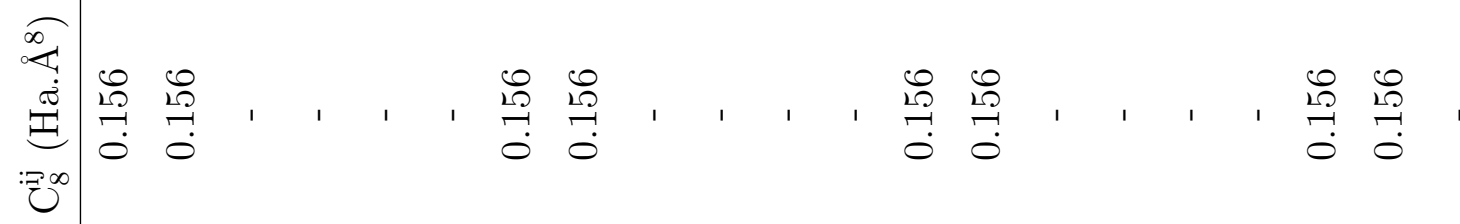

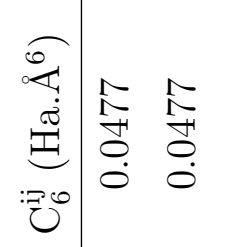

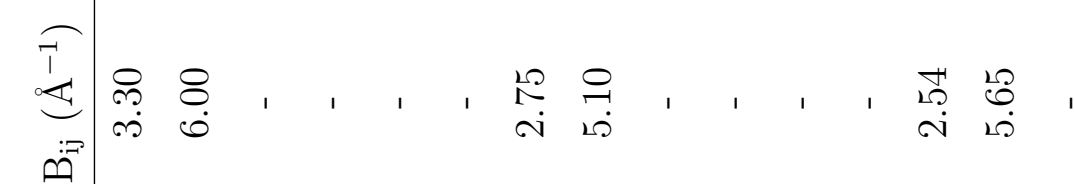

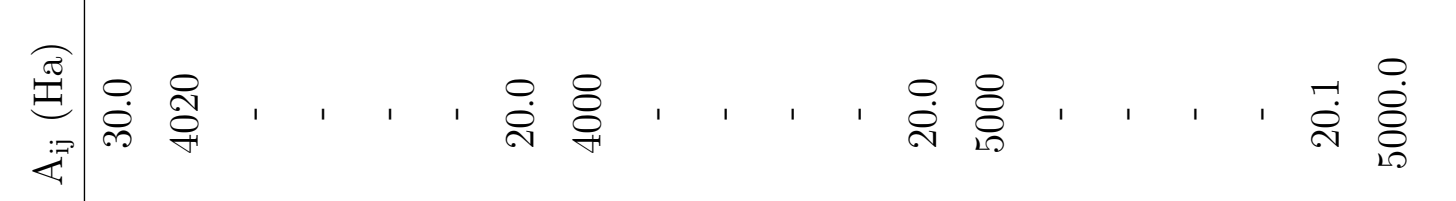

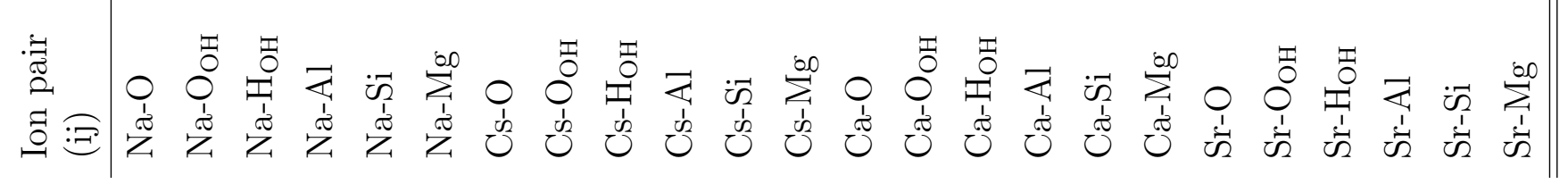

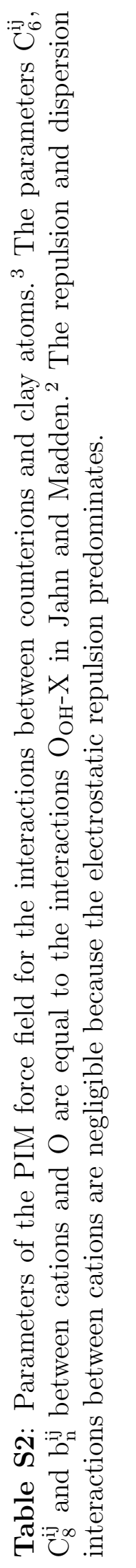


Table S3: Simulated $c v$-montmorillonites used for the comparison with XRD data. A and $\mathrm{B}$ are the box sizes and $\mathrm{h}$ is the layer-to-layer distance. $h$ parameters differ from one sample to the other due to the cation size and relative humidity considered for XRD experiments. ${ }^{4}$ Concerning water content used in the simulations, the values given by Ferrage et al. ${ }^{4}$ were considered for $\mathrm{Na}$ - and Sr-montmorillonites, whereas water content for Ca-montmorillonite was reconsidered in light of more recent results on Ca-saturated smectites ${ }^{5}$ and slightly increased from 8 to 9 per unit cell.

\begin{tabular}{cccccc}
\hline \hline $\begin{array}{c}\text { Systems } \\
\text { Cis- }\end{array}$ & $\begin{array}{c}\text { Supercell } \\
\text { dimensions }\end{array}$ & $\begin{array}{c}\mathrm{A} \\
(\AA)\end{array}$ & $\begin{array}{c}\mathrm{B} \\
(\AA)\end{array}$ & $\begin{array}{c}h \\
(\AA)\end{array}$ & $\begin{array}{c}\text { Water molecule } \\
\text { per unit cell }\end{array}$ \\
\hline Na-montmorillonite & $8 \times 4 \times 2$ & 41.44 & 35.88 & 15.52 & 9.5 \\
Ca-montmorillonite & $8 \times 5 \times 2$ & 41.44 & 44.85 & 15.18 & 9.0 \\
Sr-montmorillonite & $8 \times 4 \times 2$ & 41.44 & 35.88 & 15.73 & 9.5 \\
\hline \hline
\end{tabular}

